PONTIFÍCIA UNIVERSIDADE CATÓLICA DO RIO DE JANEIRO

O Comportamento do Consumidor Jovem de Cervejas Especiais na Zona Sul do Rio de Janeiro

João Pedro Barbosa de Lemos

Trabalho de Conclusão de Curso

Centro de CIÊNCIAS SOCIAIS - CCS

Departamento de AdministraçÃo

Graduação em Administração de Empresas 


\section{O Comportamento do Consumidor Jovem de Cervejas Especiais na Zona Sul do Rio de Janeiro}

Trabalho de Conclusão de Curso

Trabalho de Conclusão de Curso, apresentado ao programa de graduação em Administração da PUC-Rio como requisito parcial para a obtenção do titulo de graduação em Administração.

Orientador: Jorge Duro

Rio de Janeiro, Novembro de 2015. 


\section{Agradecimentos}

Agradeço a minha noiva, que abriu mão de horas de descanso para me ajudar, e muito, a concluir este trabalho. Eu te amo meu amor!

Agradeço muito aos meus grandes amigos Ettore, Ricardo e Tayana, que estiveram comigo durante todos esses anos de PUC e estarão juntos comigo daqui para frente.

Agradeço também ao professor Jorge Duro por seu apoio durante a produção do TCC. 


\section{Resumo}

LEMOS, João Pedro. O Comportamento do Consumidor Jovem de Cervejas Especiais na Zona Sul do Rio de Janeiro. Rio de Janeiro, 2015. Número de páginas:41. Trabalho de Conclusão de Curso - Departamento de Administração. Pontifícia Universidade Católica do Rio de Janeiro.

Este estudo pretende investigar quais são os principais fatores que influenciam no comportamento do jovem consumidor de cervejas especiais da Zona Sul do Rio de Janeiro. O mercado de cervejas especiais está em crescimento e as classes altas tem consumido de forma diferente, adotando as marcas mais caras e de mais qualidade. O Modelo de Análise de Hierarquias de Thomas Saaty será utilizado para que sejam descobertas as principais razões que fazem as pessoas escolherem por uma marca em detrimento da outra.

Palavras- chave

Cervejas Especiais; Mercado de Cerveja; Comportamento do Consumidor; Marketing 


\section{Abstract}

LEMOS, João Pedro. The Behavior of Young Special Beer Consumers in Rio de Janeiro's South Side. Rio de Janeiro, 2014. Número de páginas p:41 Trabalho de Conclusão de Curso - Departamento de Administração. Pontifícia Universidade Católica do Rio de Janeiro.

This present study aims to investigate which are the main motives that makes influence on the Rio de Janeiro South Side's young people consumer behavior. The special beer market is growing and the wealthy people have been consuming in a different way, drinking more expensive and quality brands. The Analytic Hierarchy Process by Thomas Saaty, will be used for reveal the main reasons why young people choose one brand instead of another.

Key-words

Special Beer; Beer Market; Consumer Behavior; Marketing 


\section{Sumário}

1. O tema e o problema de estudo 1

1.1. Introdução ao tema e ao problema do estudo 1

1.2. Objetivo do estudo 2

1.3. Objetivos intermediários do estudo 3

1.4. Justificativa e relevância do estudo 3

1.5. Delimitação e foco do estudo 4

2 Revisão de literatura 5

2.1. A Cerveja Especial 5

2.2. Estilos de Cerveja 6

2.3. O Mercado de Cervejas Especiais no Brasil 8

2.4. Comportamento do Consumidor 10

2.4.1. Definição 10

2.4.2. Influência de Variáveis Internas e Externas 10

2.4.3. Atributos de Compra 11

2.4.4. A Importância da Marca como Atributo de Compra 12

2.4.5. O Processo Decisório de Compra 13

2.4.6. Fatores Influenciadores do Comportamento de Compra do $\begin{array}{ll}\text { Consumidor } & 14\end{array}$

$\begin{array}{ll}\text { 2.5. Método de Análise de Hierarquias } & 17\end{array}$

3 Metodologia 20

3.1. Etapa de Coleta de Dados 20

3.2. Fontes de informação selecionadas para coleta de dados no $\begin{array}{ll}\text { estudo } & 20\end{array}$

3.3. Procedimentos e Instrumentos de Coleta de Dados Utilizados no $\begin{array}{ll}\text { Estudo } & 20\end{array}$

3.4. Formas de tratamento e análise dos dados coletados para o estudo21

3.5. Limitações do Método 21 
4 Resultados $\quad 22$

4.1. Perfil do Grupo de Foco 22

4.2. Marcas Utilizadas 22

4.3. A Experiência 26

4.3.1. Processo de Cálculo e Resultados 27

5 Conclusões e recomendações para novos estudos 34

5.1. Sugestões e recomendações para novos estudos 36

6. Referências Bibliográficas 37

Anexo 1 - Folha Entregue aos Participantes (3 páginas) 40

\section{Lista de Figuras}

Figura 1: Infográfico das Famílias de Cerveja ............................................. 7

Figura 2: Equação 1 e 2 ............................................................................. 19

Figura 3: Evento da Jeffrey no Leblon ....................................................... 23

Figura 4: Marketing da Brooklyn no Restaurante Meating, na Gávea ................ 24

Figura 5: Ativação da Jeffrey (e presença discreta da Delirium) no mercado Zona

Sul, no Leblon .................................................................................... 24

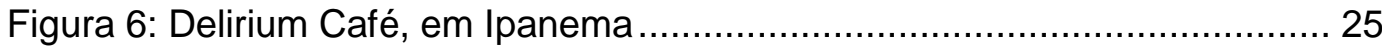

Figura 7: Exposição da Delirium no Bar Brewteco, no Leblon .......................... 25

Figura 8: Hierarquia da Pesquisa ........................................................ 27 


\section{Lista de Tabelas}

Tabela 1: Estrutura de Hierarquia............................................................. 17

Tabela 2: Pesos para Comparação ........................................................... 18

Tabela 3: Matriz de Critérios ....................................................................... 18

Tabela 4: Índice Randômico....................................................................... 19

Tabela 5: Matriz de Comparação de Critérios ................................................ 28

Tabela 6: Matriz Quadrada 1 Normalizada ................................................. 28

Tabela 7: Matriz Quadrada 2 Normalizada .................................................... 29

Tabela 8: Vetor Prioridade..................................................................... 29

Tabela 9: Matriz Propaganda .................................................................. 30

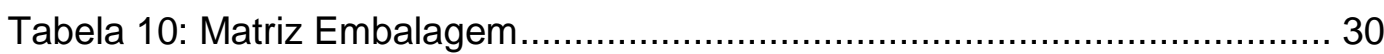

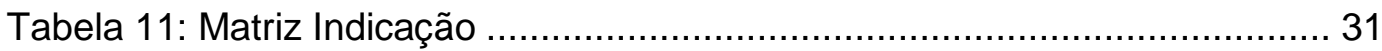

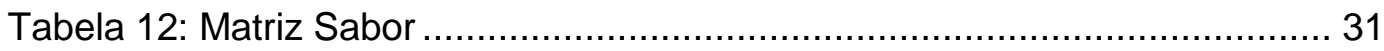

Tabela 13: Vetores Prioridade das Alternativas ............................................... 31

Tabela 14: Vetores Prioridade das Alternativas............................................. 32

Tabela 15: Matriz Decisiva ............................................................................. 33 


\section{O tema e o problema de estudo}

\subsection{Introdução ao tema e ao problema do estudo}

O povo carioca ama e cultiva o hábito de beber cerveja há muitos anos. No fim de semana, depois da praia ou do futebol, com os amigos, família, seja qual for a ocasião, a querida "cervejinha" está sempre presente. A consequência disso se reflete em números arrebatadores de vendas e consumo no Brasil. Segundo a Exame, em 4 de setembro de 2014, o país tem o terceiro maior mercado de cervejas do mundo, que consome cerca de 13 bilhões de litros e movimenta mais de 55 bilhões de reais por ano, perdendo apenas para os gigantes EUA e China, que possuem mercados consumidores consideravelmente maiores que o brasileiro.

Contudo, o velho costume vem sendo modificado com o tempo. Mas não em termos de quantidade, e sim de qualidade do produto, pois parte das pessoas passou a preferir cervejas de categoria superior. O consumidor que antes bebia Antarctica, Skol, Brahma ou Kaiser, agora desfruta de marcas como Leffe, Paulaner, Hoegaarden e centenas de outros rótulos nacionais e internacionais que passaram a fazer parte do cotidiano recente. Esse número cada vez maior de curiosos em experimentar sabores diferenciados acabou formando um mercado bastante promissor, que vem atraindo a atenção de muita gente envolvida com o mercado cervejeiro.

As cervejas especiais de fato invadiram o mercado brasileiro e, especificamente no Rio de Janeiro, pode-se dizer que estão na moda. Evidentemente, a qualidade superior se reflete no preço, que chega a ser mais de dez vezes mais caro que o de uma cerveja normal. Tal fator torna-se determinante para segmentar o público-alvo, que tende a ser composto por indivíduos de maior poder de compra.

Exatamente por isso, os bairros da Zona Sul carioca - que concentram a grande maioria das classes $A$ e $B$ da população carioca- foram o cenário perfeito para a proliferação em massa das cervejas especiais, que invadem bares e se proliferam nas prateleiras de mercados pela região. Uma matéria da Revista Exame em fevereiro de 2015 cita estudos da consultoria britânica Mintel, especializada no mercado de bebidas, que revelam um aumento de $36 \%$ 
no consumo de cervejas artesanais nos últimos três anos no Brasil. Este crescimento alarmante carrega consigo diversos outros desdobramentos.

Ao passo que o público começou a demonstrar grande voracidade no consumo de cervejas especiais, o nicho de mercado ganhou tamanho e se ramificou. Hoje não só novas micro cervejarias surgem, mas uma gama de negócios periféricos que se aproveitam do aquecimento do setor, como por exemplo, o nascimento da profissão de sommelier de cerveja e de clubes cervejeiros, seguindo modelos parecidos com a indústria do vinho, grandes festivais como o Mondial de la Biére, exposição de produtores que premia os melhores rótulos, entre outros empreendimentos, entre outros. O fato é que muita gente vem ganhando dinheiro com esse fenômeno recente e a tendência é continuar dessa forma.

Contudo, é preciso que se entendam alguns aspectos relativos ao consumo de cervejas especiais, pois o produto não é igual a uma cerveja normal e o consumidor tampouco. O que esse novo consumidor voraz busca? De que forma ele é levado ao consumo? É preciso que se descubra de que forma ele é estimulado. Para isso, o comportamento do consumidor precisa ser avaliado de forma a desvendar as melhores maneiras de captá-lo. Afinal, quais serão os fatores determinantes que fazem a diferença para o consumidor de cervejas artesanais escolher uma entre tantas marcas disponíveis?

\subsection{Objetivo do estudo}

O presente estudo tem como objetivo central desvendar como o consumidor jovem de cervejas especiais da Zona Sul do Rio de Janeiro é estimulado ao consumo, ou seja, descobrir quais são os fatores mais determinantes em seu processo de compra da bebida. 


\subsection{Objetivos intermediários do estudo}

- Primeiramente, serão introduzidos conceitos acerca do produto Cerveja, abrangendo seus diferentes tipos, classificações e famílias com o objetivo de fornecer conhecimentos suficientes para que 0 leitor saiba como diferenciar uma cerveja popular de uma cerveja especial e as razões para explicar o preço superior praticado por este nicho de mercado. Além disso, um panorama do mercado atual de cervejas especiais será traçado, a partir de artigos sobre $\mathrm{o}$ assunto.

- Posteriormente, serão abordados aspectos relativos ao comportamento do consumidor, explorando todos os fatores que moldam a forma de consumo das pessoas, seguindo conceitos de renomados autores da área, como Solomon, Kotler, Keller, entre outros.

- Por fim, será realizado uma pesquisa junto a um grupo de foco, na qual será aplicado o internacionalmente conhecido Método de Análise de Hierarquias. Nele, variáveis serão avaliadas pelos consumidores, que escolherão as que mais thes influenciam para escolher uma cerveja. O modelo irá resultar em uma escala hierarquizada de acordo com a importância de cada critério, para que sejam descobertos os fatores mais determinantes no comportamento do consumidor. Da mesma forma, será avaliado como os consumidores avaliam as alternativas que possuem dentro de cada critério, chegando-se assim ao resultado.

\subsection{Justificativa e relevância do estudo}

A relevância do estudo se dá, primeiramente, por se tratar de um assunto que está em voga no Rio de Janeiro e no Brasil, afinal, o mercado de cervejas Premium está em plena ascensão e ao que tudo indica continuará desta forma. Junto com ele, surge uma nova forma de consumo por parte dos indivíduos que, cada vez mais, procuram as marcas deste segmento e seus comportamentos ainda não foram devidamente estudados por conta do pouco tempo de vida do nicho de cervejas artesanais no país. 
Não existem muitos trabalhos acadêmicos e artigos com enfoque nos aspectos de marketing e comportamento do consumidor, portanto, existe a possibilidade de ampliar bastante a bibliografia sobre o tema.

\subsection{Delimitação e foco do estudo}

O estudo terá algumas delimitações para possibilitar uma coleta de dados que seja relevante e capaz de traduzir o mais próximo possível da realidade. Isto porque o mercado de cervejas especiais é um nicho específico de mercado, não é extremamente democratizado, logo, requer uma análise focada.

Portanto, este trabalho abordará apenas uma parcela do público jovem, considerando apenas pessoas da faixa etária entre 20 e 25 anos, de ambos os gêneros, residentes ou frequentadores da Zona Sul do Rio de Janeiro, que abrangerá especificamente os bairros da Gávea, Leblon e Ipanema.

Além disso, a análise será feita sobre consumidores de uma faixa de renda elevada, classes $A$ e $B$, que constituem o grupo de indivíduos que tem mais acesso a cervejas especiais, por serem produtos de alto valor. 


\section{Revisão de literatura}

\subsection{A Cerveja Especial}

Segundo a explicação do consultor da Pro Beer, Leandro Viu, em entrevista ao programa "lojaaovivo.tv", em 18 de março de 2015, os quatro ingredientes fundamentais para se fabricar cerveja são: água, malte, lúpulo e levedura. Ele diz que se o consumidor verificar o rótulo de uma cerveja especial, na teoria, deverão ser esses os ingredientes descritos. Contudo, nem todas as cervejas seguem este padrão. Esta, inclusive, é a grande diferença entre as cervejas normais que o público carioca está acostumado e as cervejas artesanais.

Segundo o cervejeiro Gabriel Di Martino da Cervejaria St. Gallen, em entrevista ao portal G1, em 18 de abril de 2014, a cerveja pode legalmente ser chamada de cerveja quando possui em sua fórmula no mínimo 55\% de cereais maltados e, no máximo, $45 \%$ de adjunto cervejeiro.

No entanto, ele diz que uma quantidade baixa de cereais maltados compromete bastante a qualidade do produto, pois nesses casos, as grandes cervejarias como a Ambev fazem o uso de adjuntos cervejeiros para baratear a produção e consequentemente aumentar a margem de lucro unitário do produto. Os adjuntos cervejeiros mais comumente usados são o arroz e o milho.

Enquanto isso, Gabriel Di Martino diz que as chamadas cervejas Premium são produzidas com $100 \%$ de cereais maltados, o que the confere uma qualidade superior, com maior pureza. Nas cervejas especiais, tudo é feito de forma artesanal e o tempo de produção sempre é respeitado, para que o produto final tenha a qualidade que merece. 


\subsection{Estilos de Cerveja}

Segundo o consultor Leandro Viu, da Pro Beer, existem cerca de 130 estilos de cerveja, o que tende a confundir bastante o consumidor leigo, pois existem grandes variações em diversos aspectos como sabor, aroma, teor alcoólico, cor, amargura, entre outros. Existe até a temperatura perfeita recomendada para consumo, segundo ele, que varia de acordo com o estilo da cerveja.

Segundo matéria do site Gel Chopp, a primeira diferenciação para que se entendam os tipos diferentes de cerveja está no processo de fermentação. Existem dois tipos de fermentação que formam as duas grandes famílias de cerveja: Alta fermentação, conhecida como "Ale", e baixa fermentação, conhecida como "Lager".

Segundo o site Infobeer, A família Ale é composta por cervejas originadas de fermentações onde é utilizada a levedura do tipo sacaromices cerevisae ou similares que tenham mesmo comportamento que dá origem ao seu nome. Ao final do processo de fermentação forma-se uma camada de grossa espessura de fermento sobre a superfície do líquido e, simultaneamente, outra parte sedimenta no fundo do tanque. A fermentação alta é feita sob temperaturas mais elevadas, cerca de $18^{\circ} \mathrm{C}$ e dura entre 4 a 5 dias. As cervejas fermentadas a partir desta levedura possuem aroma mais perfumado.

Já as cervejas de baixa fermentação, as Lager, são cervejas fermentadas com sacaromices uvarum, levedura que no final do processo se deposita em uma camada no fundo do tanque de produção. Trata-se de uma fermentação que demanda mais tempo, cerca de 8 a 9 dias, produzida sob temperaturas mais baixas, por volta de $12^{\circ} \mathrm{C}$. As cervejas Lager tem aroma mais discreto, diferente das Ale.

Ainda, segundo o site diz-se que atualmente, a família Lager prevalece no cenário mundial, sendo bem mais vendida que a Ale, devido principalmente ao estilo Pilsen, em alemão Pilsner, que é cerveja com a cor dourada clara mais conhecida pelo público no Brasil.

As cervejas comuns, como Skol, Brahma e Antarctica, por exemplo, levam no rótulo o nome do estilo Pilsen. Entretanto, segundo o consultor Leandro Viu, este nome não é aferido corretamente a elas, que na realidade se enquadram no estilo Standart American Lager.

Para ajudar a organizar e esquematizar os estilos de cerveja, a imagem a seguir resume o panorama geral, com os principais estilos da atualidade: 


\section{THE WIDE WORLD OF BEER}

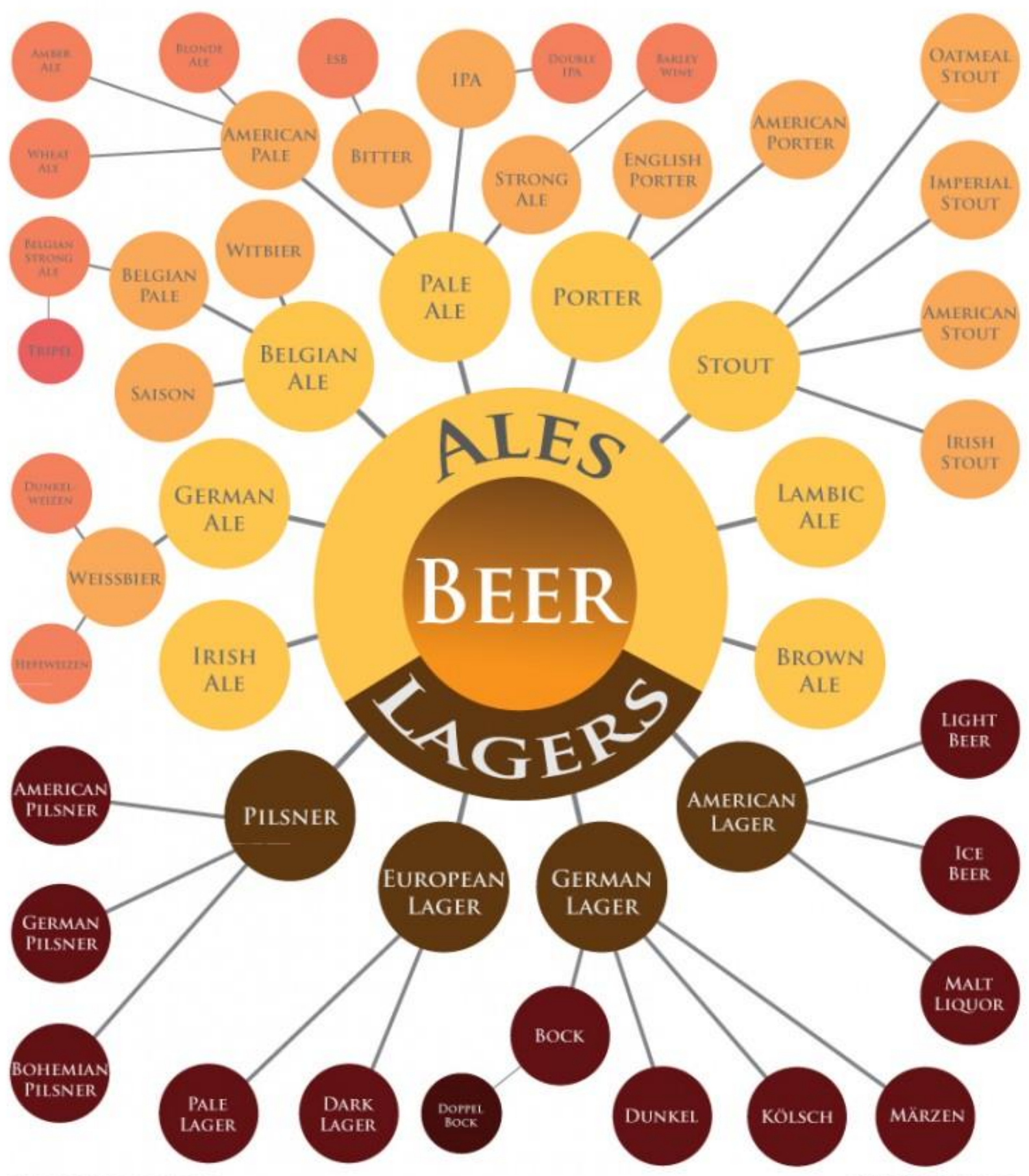

SEIDELLWORDPRESS.COM

Q2013 SEAN SEIDELI.

Figura 1: Infográfico das Famílias de Cerveja (fonte:infobeer.net) 


\subsection{O Mercado de Cervejas Especiais no Brasil}

Na primeira década dos anos 2000, a produção cervejeira total no Brasil cresceu $64 \%$, saltando de 8,2 bilhões para 13,4 bilhões de litros anuais, segundo estudos do Sistema de Controle de Produção de Bebidas da Receita Federal (Sicobe). Trata-se de um mercado em franca ascensão: o Brasil ocupa a terceira posição no ranking mundial de produtores, atrás de Estados Unidos e China e superando Alemanha - grande potência com enorme tradição no mercado de cerveja - e Rússia. Entretanto, o mercado de cervejas especiais ainda representa uma porcentagem pequena dessa estatística.

Segundo Gabriel Di Martino da cervejaria St. Gallen Segundo o cervejeiro Gabriel Di Martino da Cervejaria St. Gallen, em entrevista ao portal G1, em 18 de abril de 2014, atualmente, no Brasil, as cervejas especiais correspondem a cerca de $6 \%$ das vendas totais de cervejas. Contudo, é importante frisar que há cinco anos, esse número era de $1,5 \%$ a $2 \%$, no máximo, ou seja, o crescimento é bastante significativo.

O site G1 disse em matéria de abril de 2014, que em países como Alemanha e Estados Unidos não há crescimento percebido neste mercado, enquanto no Brasil, se a renda da população aumenta, o consumo segue o mesmo ritmo. Mais uma razão para se acreditar no futuro sustentável das cervejas especiais. A mesma reportagem, diz: "Está claro para os cervejeiros do Brasil: nos últimos anos, percebe-se uma modificação na produção do estilo de cervejas no país. Enquanto há cerca de 10 anos praticamente todas as cervejas produzidas em território nacional eram consideradas mainstream, agora o cenário mudou, pois pequenas cervejarias demonstram fôlego no mercado (...). E não são apenas as brasileiras. Pequenos lotes de micro cervejarias importadas (...) estão competindo no mercado nacional junto com os produtos brasileiros de qualidade. Assim, as prateleiras de cervejas ficam cada vez mais parecidas com as de vinho: muita opção para um público cada vez mais exigente por produtos de qualidade. Fica evidente que o consumidor evoluiu, assim como a produção nacional".

Em matéria da Exame, em 4 de setembro de 2014, Jonny Forsyth, analista global de bebidas da Mintel, reiterou que se trata de um nicho de mercado bastante atraente para quem quer empreender na cadeia cervejeira. Dados da Associação Brasileira de Bebidas (Abrabe) de 2014 confirmam o discurso de Forsyth. A entidade estima que existam hoje cerca de 230 micro cervejarias em 
atividade no país, porém, elas representam apenas $0,15 \%$ do setor cervejeiro nacional, dominado por grandes empresas com produções infinitamente maiores em escala. A gigante Ambev adota a prática arrojada de comprar marcas que se destacam no cenário nacional, incorporando-as no seu portfólio e ganhando mais fatias de mercado. Um exemplo foi a compra recente da cerveja Colorado, que já possui um nome forte no mercado.

O site do Estadão, em matéria divulgada no dia 25 de setembro de 2013, listou as oportunidades no mercado cervejeiro especial, que são múltiplas e em diversas etapas da cadeia produtiva e comercial, dentre elas estão:

1. Produção de Cerveja: A fabricação da cerveja é a possibilidade mais óbvia de entrar neste nicho de mercado, entretanto, abrir uma nova cervejaria exige um investimento inicial de pelo menos $R \$ 200$ mil, o que se configura como uma barreira de entrada para novos empreendedores.

2. Terceirização de Produção: O plano B para quem não tiver expertise ou capital suficiente para montar sua estrutura própria é a terceirização. Neste caso, encaminha-se o setor produtivo a uma fábrica já estabelecida, que já possui todo o maquinário e know how necessário para a produção da cerveja. Esta prática que vem sendo bastante utilizada por várias novas marcas que ganharam o nome de cervejarias ciganas.

3. Varejo: Apostar em um estabelecimento comercial que venda cervejas artesanais é outro caminho viável. Ter um restaurante ou bar com uma carta de cervejas especiais variadas, algo que vem sendo muito explorado, principalmente na Zona Sul carioca. O problema, nesse caso, é a grande concorrência no mercado, cabe ao local conseguir se destacar dentre os outros.

4. Importação: Nesse caso, o empresário lidará com custos elevados de operação, principalmente com a disparada recente do dólar, grande quantidade de taxas e impostos (lembrando que o Brasil está entre os países que mais cobra tributos no mundo) e com legislação complicada.

5. Outras opções: Entre as outras opções de negócio neste nicho estão os clubes de assinaturas como o Have a Nice Beer, CluBeer e muitos outros. Além disso, o comércio online pode ser uma boa aposta para quem deseja empreender por representar custos bem reduzidos em relação a algumas opções acima. Neste caso, os associados pagam 
uma mensalidade de cerca de 70 reais e recebem em casa um kit com 4 garrafas de 2 marcas diferentes e uma revista sobre cerveja. Estas marcas normalmente são exclusivas ou em primeira mão, segundo Rafael Borges, Pedro Meneghetti e Rodrigo Sztelzer, sócios do Have a Nice Beer.

\subsection{Comportamento do Consumidor}

\subsubsection{Definição}

O comportamento do consumidor é o estudo responsável por analisar como as pessoas compram, por que razão compram, quando compram, onde compram, com que frequência e com que assiduidade usam o que compram (SCHIFFMAN; KANUK, 2000).

\subsubsection{Influência de Variáveis Internas e Externas}

Entretanto, Barros (2004) estende o conceito acima, dizendo que o consumo vai além do processo de selecionar, adquirir e se utilizar dos benefícios de um bem ou serviço. Também é possível entendê-lo como uma combinação de elementos tangíveis e intangíveis no qual a individualidade dos participantes está disposta em um conjunto de relações sociais e culturais, necessitando ser compreendida, como um fato social.

Kotler e Keller (2006) seguem na linha de Barros, entendendo que há influências acima da individualidade definindo a forma das pessoas consumirem. Eles dizem que "o comportamento do consumidor pode ser influenciado por diversos fatores dos quais podem ser citados: os culturais, sociais, pessoais e psicológicos, sendo os fatores culturais que exercem maiores influências", ou seja, a forma de consumo de um indivíduo está intimamente ligada à forma que seu grupo consome. Todo ato de consumo tem uma repercussão social e por isso, pode ser examinado do ponto de vista coletivo e não somente individual.

Solomon (2002, p. 257) diz que "um grupo de referência é um indivíduo ou grupos reais ou imaginários, concebidos como tendo relevância significativa sobre as avaliações, aspirações ou comportamento de um indivíduo". 
Na definição de Limeira (2007), o comportamento do consumidor abrange as várias informações e reações dos indivíduos, como consequência de múltiplos aspectos e estímulos, como o marketing, por exemplo, que influencia o ato de compra de produtos pelos consumidores.

As opiniões e conceitos que permeiam o meio social onde o consumidor está inserido significam os fatores ambientais. Em complemento, Limeira (2007) destaca ainda a existência de vários aspectos psicológicos que exercem influência sobre o comportamento de compra do cliente, que são:

a) Motivação:

Ocorre por fatores internos ou externos (ambiente, sociedade ou necessidade fisiológica/social) que levam o consumidor a ter determinado comportamento e criam um dado que será memorizado sensorialmente, temporariamente ou permanentemente;

b) Envolvimento:

É a importância ou o interesse que o consumidor apresenta em relação ao produto;

c) Percepção:

É a seleção, organização e a interpretação das sensações do consumidor. Esse processo ocorre em três etapas: exposição, atenção e interpretação;

d) Aprendizagem:

Influencia o comportamento do consumidor pois abrange a "bagagem" que o indivíduo carrega.

\subsubsection{Atributos de Compra}

Segundo Francischelli (2009), os atributos relativos a um produto significam um dos aspectos de maior importância na decisão de compra do indivíduo, pois em grande parte das vezes os consumidores compram baseados nos atributos apresentados pelo objeto de compra. Dessa forma, o autor considera essencial o estudo destes atributos, para que seja possível alinhar-se com as crenças do cliente. 
Francischelli (2009) diz que tais atributos definem o produto, suas características, funções e componentes. Observa-se que as características, funções e componentes do produto são fatores decisivos na opção de compra do consumidor, quando coincidem com suas preferências e características individuais, inclusive aspectos relacionados com a sua participação no meio social.

Mattos (2007) diz que o processo decisório de compra é intimamente influenciado pelos atributos, principalmente quando o cliente busca vai ao mercado em busca de opções. Nesta fase, a pessoa identifica várias características que considera importantes para que a compra seja realizada, levando em conta a importância de cada uma. Assim, a compreensão dos atributos é imprescindível para que se entenda os fatores capazes de motivar o cliente a escolher um produto ou serviço.

\subsubsection{A Importância da Marca como Atributo de Compra}

Segundo Kotler e Keller (2006) a marca representa acima de tudo um compromisso da empresa no sentido de ofertar ao consumidor determinados atributos, benefícios e serviços de forma uniforme e coerente, podendo apresentar os seguintes níveis de significado: atributos, benefícios, valores, cultura, personalidade e usuário.

Os valores, a cultura e a personalidade são os fatores mais duradouros, pois dizem respeito à essência de uma marca. Churchill e Peter (2000 apud FRANCISCHELLI, 2009) consideram a marca como uma palavra capaz de identificar um produto ou serviço de uma organização, diferenciando-o das demais. Assim, a criação de marcas tem como principal objetivo diferenciar os bens produzidos, o que ajuda os consumidores no momento da decisão de compra. Churchill e Peter (2000 apud FRANCISCHELLI, 2009) dizem que a vantagem de utilização da marca é ser a forma mais simples de distinção dos produtos na mente do consumidor, algo que pode diminuir o esforço e o gasto de tempo do cliente no processo de compra.

Para Kotler e Armstrong (2008) a marca visa traduzir o valor que o produto representa para o consumidor. Retrata também a visão e sentimentos do indivíduo em relação ao bem. A força de uma marca muda em função da capacidade de conquistar a preferência, simpatia e a fidelidade do consumidor. 


\subsubsection{O Processo Decisório de Compra}

$\mathrm{Na}$ ótica de Solomon (2008), o processo de decisão de compra se desenvolve em 5 fases, da seguinte forma:

a) Reconhecimento do problema: identificação de necessidade ou problema, ou seja, é a diferença - o gap - percebida pelo consumidor entre a situação de momento e a situação em que ele visa estar.

b) Busca de informações: Segundo Neves (2009), a partir da identificação do problema, baseado em suas necessidades próprias, o cliente busca informações sobre como se satisfazer. A busca de informações baseia-se nas experiências passadas e na confiança das informações anteriormente obtidas.

c) Segundo Neves (2009), Avaliação das alternativas: no processo de decisão de compra são utilizadas novas avaliações como também aquelas que fazem parte de experiências anteriores do consumidor.

d) Escolha do produto ou decisão de compra: Segundo Rennó (2009), o processo de compra pode ser concluído em qualquer fase, quando a necessidade não mais existir ou mesmo se o cliente concluir que as alternativas existentes são inadequadas para resolver o problema identificado.

e) Avaliação pós compra: a satisfação do consumidor é o resultado esperado, o que significa que o desempenho do produto corresponda às expectativas do cliente. Neves (2009) ressalta que os resultados verificados após a venda do produto são: consumo, avaliação pós-consumo e descarte.

Rennó (2009) diz que o consumo pode ocorrer ainda na loja ou em situação posterior. A avaliação pós-consumo significa a fase em que o cliente sente a satisfação, o que ocorre quando suas expectativas são correspondidas, ou insatisfação, quando ocorre o contrário. O descarte envolve alternativas como reciclagem, descarte completo ou revenda. 


\subsubsection{Fatores Influenciadores do Comportamento de Compra do Consumidor}

Segundo Solomon (2008), um dos principais pontos do comportamento do consumidor atualmente é o fato dos compradores adquirirem produtos mais pelo que representam do que por sua utilidade. Portanto, é importante a compreensão do comportamento do consumidor, tendo em vista que o próprio não reconhece seus motivos mais profundos ou os fatores que podem influenciá-lo na opção por um ou outro produto.

Esta compreensão ocorre mais facilmente através dos fatores motivacionais, culturais, sociais, pessoais e psicológicos.

a) Fatores culturais:

Para Souza, Farias e Nicoluci (2005), a cultura tem profunda influência no comportamento das pessoas, pois se tratam de valores adquiridos desde a infância, que acompanham todo o processo de socialização do indivíduo, assim como a classe social onde este se insere.

Cada cultura é formada por subculturas, que fornecem identidade e socialização mais especifica para os integrantes. Subculturas podem ser classificadas a partir da nacionalidade, religião, grupos étnicos e regiões geográficas. Deste modo, os aspectos culturais exercem muito mais influência do que parece, agindo decisivamente no comportamento das pessoas de forma geral e, pontualmente, no que diz respeito à decisão de compra, pois as subculturas citadas pelos autores interferem na preferência de um consumidor por determinado produto ou serviço.

Souza, Farias e Nicoluci (2005) dizem que os profissionais de marketing idealizam produtos pensando especificamente em grupos que possuem subculturas marcantes, pois desta forma conseguem agradar os consumidores, principalmente os brasileiros que por fazerem parte de um país tão diverso, podem encontrar produtos que se ajustem especificamente aos seus credos, localização geográfica, estilo de vida, e ao seu status social.

b) Fatores sociais

Solomon (2008) diz que os fatores sociais são representados pelos grupos de referência que influenciam bastante na decisão de compra das pessoas. Os grupos de referência fazem influência direta - face a face - ou indireta sobre o 
comportamento do indivíduo. Os grupos que exercem influência direta recebem o nome de grupos de afinidade.

Segundo Kotler e Keller (2006, p. 185), alguns grupos de afinidade são primários, como família e amigos, com os quais a pessoa tem uma interação contínua e informal. As pessoas também fazem parte de grupos secundários, como grupos religiosos e profissionais que normalmente são formais e exigem menor interação contínua. A convivência social junto aos grupos de referência desenvolve o comportamento das pessoas, influenciando diretamente suas decisões e preferências de compra, por causa do contato direto e constante entre os indivíduos.

Segundo Souza, Farias e Nicoluci (2005), os indivíduos são influenciados diretamente por grupos de referência de formas distintas. Podem ser expostos a novos comportamentos e a estilos de vida diferentes, podem receber influências relativas a autoimagem e podem receber pressões sobre a conformidade em relação às regras sociais, fatores que contribuem para que surja uma preferência por determinado produto. Assim, os profissionais de marketing estudam os grupos de referência do público alvo desejado, dando foco em seus líderes para que divulguem informalmente seus produtos.

c) Fatores pessoais

Kotler e Armstrong (2008, p. 125) dizem que "o ato de comprar é moldado também pelo estágio do ciclo de vida da família, estágios pelos quais as famílias passam à medida que seus membros amadurecem". Desta forma, dentre os diversos fatores que influenciam o comportamento de compra, a família pode ser citada como um fator-chave em função do convívio.

Destacam-se também a ocupação e situação financeira. Segundo Kotler e Keller (2006), a ocupação também possui influência no padrão de consumo de um indivíduo. Desta forma, pode-se dizer que os produtos adquiridos por alguém que exerce uma ocupação simples tenderão a serem baseados na simplicidade, sendo compatíveis com o salário e com a ocupação, da mesma forma que um funcionário de alta renda compra produtos caracterizados pelo luxo.

Segundo Kotler e Keller (2006, p. 191) "um estilo de vida é o padrão de vida da pessoa expresso por atividades, interesses e opiniões. O estilo de vida representa a pessoa por inteiro, interagindo com seu ambiente". Por isso, as empresas visam conectar seus produtos a um estilo de vida, como forma de atingir um público alvo específico. 
Kotler e Keller (2006) dizem que a personalidade é uma variável bastante útil para analisar o comportamento do consumidor, uma vez que os tipos de personalidade podem ser identificados e que existem relações diretas entre tipos de personalidade e escolhas de produtos e marcas. Devido a isso, observa-se que cada pessoa tem uma personalidade singular e que produz estímulos diferentes em relação à decisão de compra. Desta forma, as estratégias de marketing produzem anúncios relacionados a consumidores que apresentam determinadas características, como autonomia e autoconfiança, por exemplo.

Segundo Schiffman e Kanuk (2005), a personalidade de um indivíduo é composta pelas características individuais que a diferem das outras. Tais características representam fatores que influenciam o consumidor em seus hábitos de compra e sua identificação permite às organizações posicionarem seus produtos de maneira mais eficiente.

\section{d) Fatores psicológicos}

Segundo Souza, Farias e Nicoluci (2005), os fatores psicológicos como motivação, percepção, aprendizagem e atitudes apresentados por um cliente podem ter significados relevantes em seu comportamento de compra.

Os autores acima dizem ainda que a motivação representa uma situação de tensão psicológica que prepara a pessoa para a ação. Ela ocorre a partir do surgimento de uma necessidade, que estimula fatores externos ou internos, levando o indivíduo a agir após a identificação de certa necessidade, com o objetivo de reduzir a tensão, que por sua vez elimina a necessidade inicial.

Para Samara e Morsch (2005), a percepção corresponde a um processo em que as pessoas vivem sensações através de mensagens que captam seu interesse, dentre todas as outras no entorno. Os sentidos humanos correspondem aos estímulos através de sensações, que podem ocorrer em maior ou menor intensidade, dependendo de fatores como o ambiente onde está.

Segundo Solomon (2008), a atitude representa um julgamento pessoal abrangente e duradouro aplicável a diversos acontecimentos da vida e que dura bastante tempo. O julgamento ocorre por parte do consumidor sobre si próprio e sobre as outras pessoas, assim como em relação a produtos, serviços, publicidade etc. 


\subsection{Método de Análise de Hierarquias}

O Método de Análise Hierárquica (MAH), desenvolvido na década de 1980 por Thomas L. Saaty, da Universidade da Pensilvânia é o adotado neste estudo para a geração dos pesos das chamadas funções-objetivo. O método tem como objetivo facilitar a atribuição de variáveis qualitativas e subjetivas dentro de fatores quantitativos para o processo de tomada de decisão.

O MAH procura hierarquizar os objetivos por meio de comparações, ou seja, a preocupação está na obtenção de pesos numéricos para alternativas com relação a sub-objetivos e para sub-objetivos com relação a objetivos de ordem mais elevada numa escala hierárquica.

Os problemas são estruturados da seguinte forma:

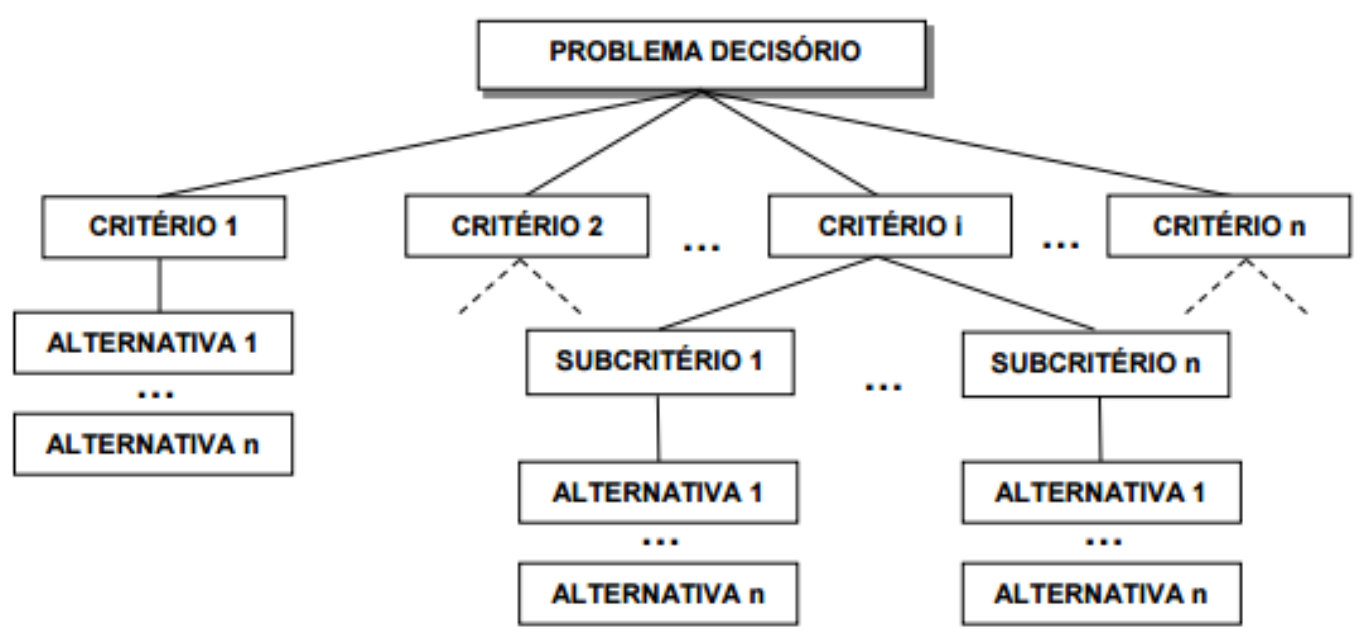

Tabela 1: Estrutura de Hierarquia (fonte: www.maxwell.vrac.pucrio.br/17608/17608_5.PDF)

No caso deste trabalho, o problema decisório que se deve descobrir é a escolha de marca de cerveja artesanal, os critérios são os elementos que influenciam no consumo dos indivíduos e as alternativas são as três marcas escolhidas para realizar a pesquisa com o grupo de foco.

Os pesos aplicados para comparação são dados de acordo com o quadro abaixo: 


\begin{tabular}{|c|c|}
\hline $\begin{array}{c}\text { ESCALA } \\
\text { NUMÉRICA }\end{array}$ & $\begin{array}{c}\text { ESCALA } \\
\text { VERBAL }\end{array}$ \\
\hline 1 & $\begin{array}{c}\text { Mesma } \\
\text { importância }\end{array}$ \\
\hline 3 & $\begin{array}{c}\text { Importância } \\
\text { moderada de um } \\
\text { sobre o outro }\end{array}$ \\
\hline 5 & $\begin{array}{c}\text { Importância } \\
\text { essencial ou forte }\end{array}$ \\
\hline 7 & $\begin{array}{c}\text { Importância muito } \\
\text { forte }\end{array}$ \\
\hline 9 & $\begin{array}{c}\text { Importância } \\
\text { extrema }\end{array}$ \\
\hline
\end{tabular}

Tabela 2: Pesos para Comparação (fonte: www.maxwell.vrac.pucrio.br/17608/17608_5.PDF)

Estes pesos são aplicados aos critérios, que são comparados em matrizes como a apresentada abaixo, na qual todos tem um peso relativo a outro:

\begin{tabular}{|c|c|c|c|c|c|}
\hline & Critério 1 & Critério 2 & Critério 3 & Critério 4 & Critério 5 \\
\hline Critério 1 & 1 & 1 & 5 & 7 & 5 \\
\hline Critério 2 & 1 & 1 & 3 & 7 & 3 \\
\hline Critério 3 & $1 / 5$ & $1 / 3$ & 1 & 5 & 3 \\
\hline Critério 4 & $1 / 7$ & $1 / 7$ & $1 / 5$ & 1 & $1 / 5$ \\
\hline Critério 5 & $1 / 5$ & $1 / 3$ & $1 / 3$ & 5 & 1 \\
\hline
\end{tabular}

Tabela 3: Matriz de Critérios (fonte: www.maxwell.vrac.puc-rio.br/17608/17608_5.PDF)

Para apuração do resultado são realizados cálculos algébricos matriciais até que se chegue a um peso final de cada variável. Os cálculos serão melhor detalhados na parte de resultados, no capítulo 4.

Para Schoemaker e Waid (1982), a grande vantagem do MAH está em sua habilidade em manusear problemas complexos da vida real e em sua facilidade de uso.

Outra vantagem a ser observada está no fato de que o MAH é uma ferramenta frequentemente apreciada para decisão com múltiplos critérios. Isto porque ele possibilita considerações sociais, culturais e outras não econômicas que serão incorporadas no processo de tomada de decisão. 
Existe ainda a questão da consistência das comparações, nas quais é difícil obter um índice perfeito de coerência. Segundo Lopes, Coelho e Libânio (2011), para que seja determinada a consistência de uma matriz de comparações, devese calcular a razão de consistência $(R C)$, na qual valores inferiores a 0,10 são satisfatórios.

O cálculo de RC começa com a determinação de $\lambda \max$ (autovalor máximo) que é estimado da seguinte forma:

I. Multiplicar matriz de comparações paritárias pelo vetor de prioridades, obtendo-se assim um novo vetor;

II. Dividir o primeiro valor deste vetor pelo primeiro valor do vetor de prioridades, o segundo componente do novo vetor pelo segundo componente do vetor de prioridades, e assim sucessivamente, para se obter um novo vetor;

III. A soma dos valores deste vetor deverá ser dividida pelo número de elementos, resultando em uma aproximação para $\lambda \max$.

Quanto maior a proximidade o valor de $\lambda$ max tiver de $\mathrm{n}$ (ordem da matriz), mais consistência terá o resultado. O desvio de consistência, denominado de índice de consistência (IC) é fornecido pela Equação 1 e a razão de consistência $(R C)$ é dada pela equação 2.

$$
\mathrm{IC}=\frac{\lambda_{\text {max }}-\mathrm{n}}{\mathrm{n}-1} \quad \mathrm{RC}=\frac{\mathrm{IC}}{\mathrm{IR}}
$$

Figura 2: Equação 1 e 2 [Fonte: Lopes, Coelho e Libânio (2011)]

O IR é o índice randômico, obtido através de cálculos utilizando amostras de tamanho 100 e 500 , para matrizes de ordem até $15 \times 15$

\begin{tabular}{cc|cc|cc}
\hline Ordem & IR & Ordem & IR & Ordem & IR \\
\hline 1 & 0,00 & 6 & 1,24 & 11 & 1,51 \\
2 & 0,00 & 7 & 1,32 & 12 & 1,48 \\
3 & 0,58 & 8 & 1,41 & 13 & 1,56 \\
4 & 0,90 & 9 & 1,45 & 14 & 1,57 \\
5 & 1,12 & 10 & 1,49 & 15 & 1,59 \\
\hline
\end{tabular}

Tabela 4: Índice Randômico [Fonte: Lopes, Coelho e Libânio (2011) ] 


\section{Metodologia}

\subsection{Etapa de Coleta de Dados}

A etapa de coleta de dados foi realizada por meio de uma experiência com um grupo de foco de 10 (dez) pessoas que responderam questões de preferência em relação a três marcas de cerveja artesanal.

\subsection{Fontes de informação selecionadas para coleta de dados no estudo}

Os entrevistados foram indivíduos enquadrados no perfil de público-alvo no qual este trabalho está focado, portanto:

- Pessoas com idade entre 20 e 30 anos;

- Moradores e/ou frequentadores da Zona Sul do Rio de Janeiro;

- Pertencentes às classes $\mathrm{A}$ e $\mathrm{B}$;

- Consumidores de cerveja artesanal.

A seleção dos candidatos foi feita através de convite em redes sociais, a maioria deles se conhecia, mas não tinham relações próximas.

\subsection{Procedimentos e Instrumentos de Coleta de Dados Utilizados no Estudo}

Os entrevistados foram reunidos presencialmente e as três cervejas selecionadas para o experimento foram expostas e depois degustadas pelos participantes, sabendo-se que todos eles já experimentaram todas as marcas anteriormente. As marcas utilizadas foram: Delirium Tremens, Jeffrey Niña e Brooklyn Lager, que serão dissecadas mais adiante no capítulo 4.

Os participantes foram apresentados aos tipos das cervejas e suas características e degustaram em seguida. Logo após isto, eles preencheram uma folha com as matrizes do $\mathrm{MAH}$, que lhes foi entregue alguns minutos após o contato com as cervejas. Os entrevistados indicaram o peso que as variáveis têm em relação às outras. 
Primeiramente, eles preencheram a matriz dos critérios de comportamento do consumidor e, posteriormente, a matriz das alternativas dentro de cada critério.

\subsection{Formas de tratamento e análise dos dados coletados para o estudo}

Os dados coletados nas entrevistas foram inseridos no Método de Análise de Hierarquias de Thomaz Saaty.

Segundo a metodologia, os fatores escolhidos foram comparados em pares, todos com todos, gerando uma classificação por ordem de importância, resultando em um ranking de fatores que influenciam no processo decisório organizados hierarquicamente.

\subsection{Limitações do Método}

As limitações que desafiaram o trabalho de obtenção de dados foram relativas ao grupo de foco. É possível que haja alguma falha de entendimento ou engano no momento de preencher as matrizes, o que pode acarretar em um resultado levemente desajustado com a realidade.

Outra limitação é o esquecimento de algum critério de comportamento do consumidor que influencie na compra de cervejas artesanais, mas por ser sutil, as pessoas tendem a esquecê-lo. 


\section{Resultados}

\subsection{Perfil do Grupo de Foco}

O grupo de foco foi escolhido sob as premissas de idade, classe social e localização geográfica deste trabalho. No total foram selecionados 10 pessoas, 7 homens e 3 mulheres.

\subsection{Marcas Utilizadas}

As Cervejas utilizadas na degustação foram as seguintes:

a) Delirium Tremens

- Cervejaria: Huyghe (Bélgica)

- Estilo: Belgian Golden Strong Ale, dourada levemente turva

- Teor Alcoólico: 8,5\%

- Temperatura ideal: 5-7ํㅡ

b) Brooklyn Lager

- Cervejaria: Brooklyn Brewery

- Origem: BrazilWays

- Estilo: Vienna Lager

- Teor Alcoólico: 5,2\%

- Temperatura ideal: 5-7ํㅡ

c) Jeffrey Niña

- Cervejaria: Jeffrey Beer, RJ - Brasil

- Estilo: Witbier (Ale), toque de limão siciliano e coentro

- Teor Alcoólico: 5,3\%

- Temperatura ideal:5-7ํㅡ

A escolha destas cervejas se deu em virtude, de dois motivos: primeiramente que as cervejas possuíssem famílias distintas (Ale e Lager), para que pudesse 
ocorrer uma comparação das preferencias; e que as cervejas fossem marcas que se equiparassem em termos de presença no mercado da Zona Sul do Rio de Janeiro e em conhecimento dos participantes do estudo.

O sabor de cada uma delas também possui uma peculiaridade própria, a Delirium Tremens possui sabor frutado, enquanto a Jeffrey possui toque cítrico e a Brooklin possui sabor suave e adocicado de malte levemente queimado.

Outro fator interessante é a nacionalidade diferente delas, uma é Americana (Brooklyn), outra Brasileira (Jeffrey) e uma Belga (Delirium). Toda essa diversidade teve como objetivo testar o comportamento do consumidor jovem frente à uma amostra da variedade que o mercado de cervejas especiais oferece.

Nas imagens abaixo é possível ver a presença das três marcas escolhidas na Zona Sul do Rio de Janeiro, em locais que os jovens consumidores costumam frequentar. Cada uma busca de forma diferente, conquistar o público-alvo.

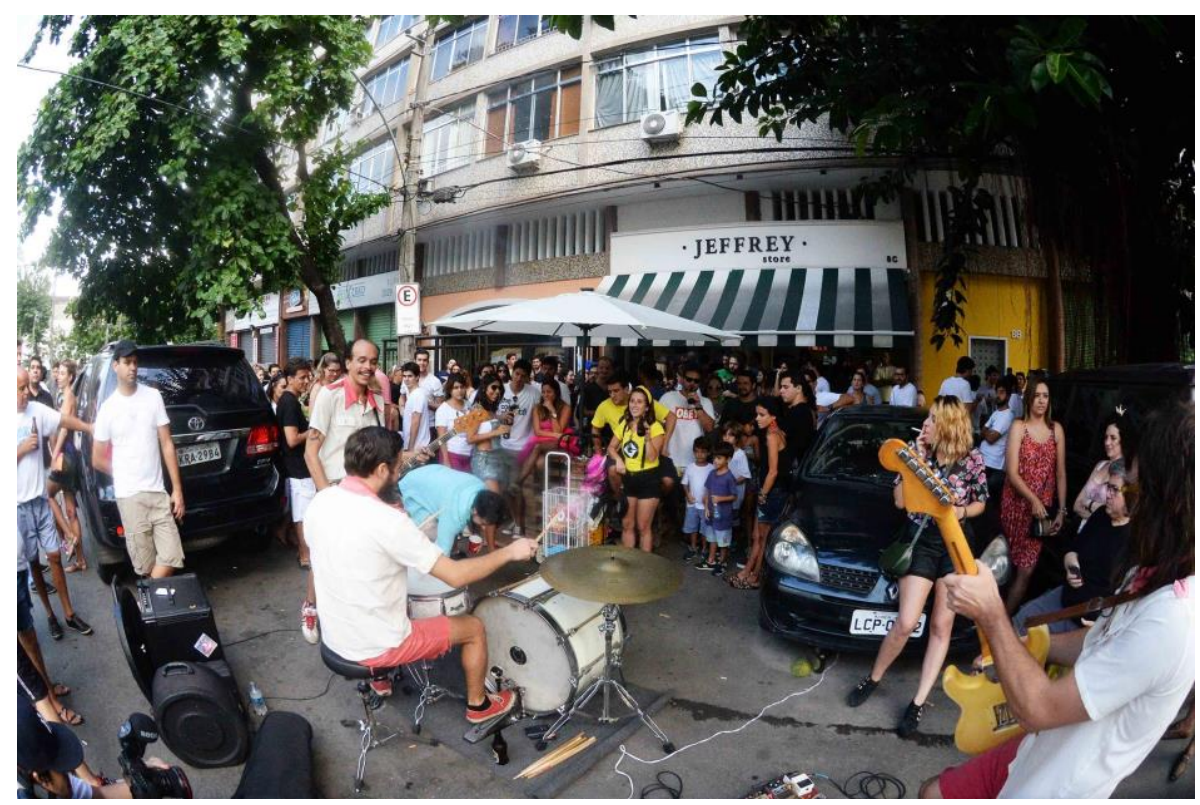

Figura 3: Evento da Jeffrey no Leblon 


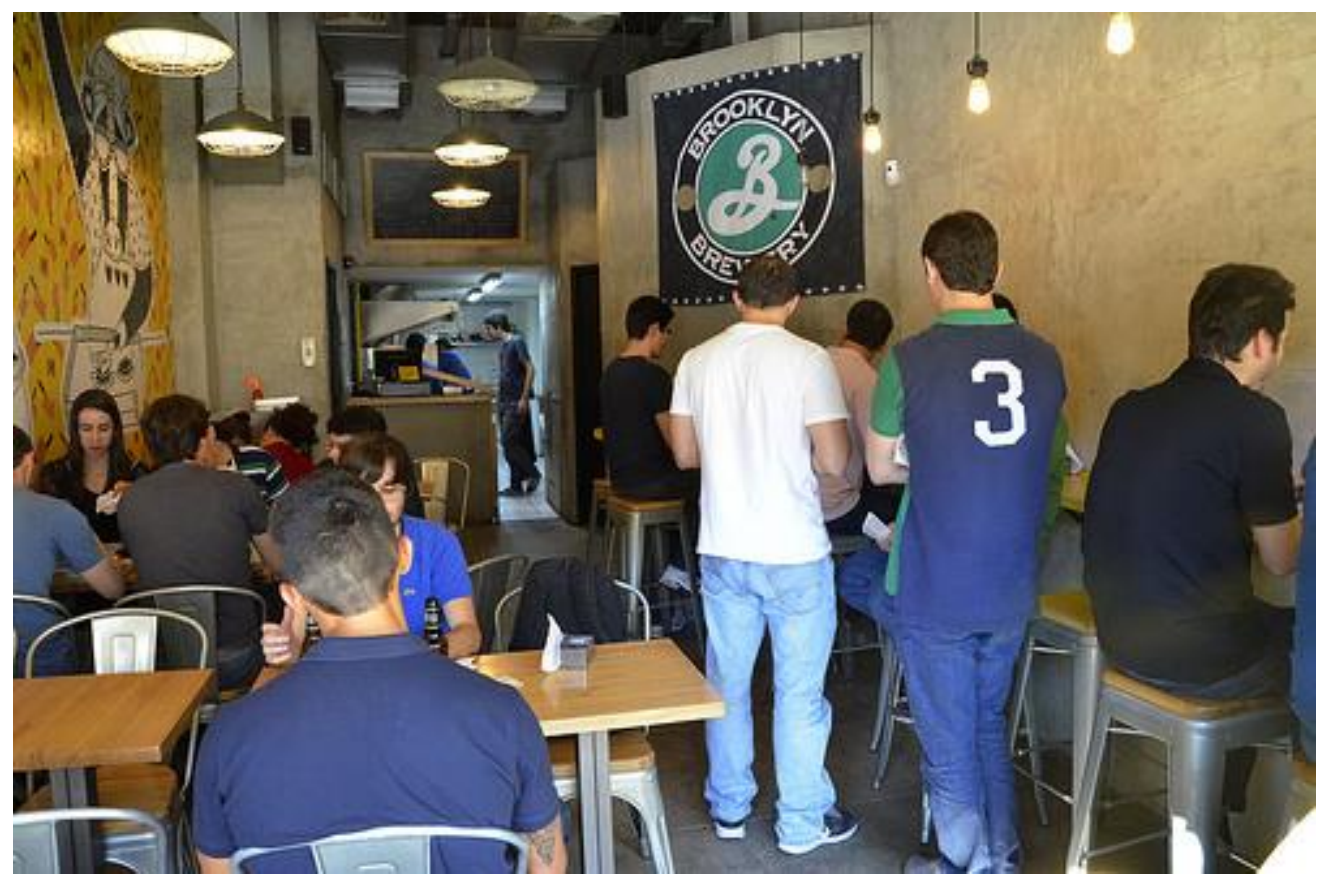

Figura 4: Marketing da Brooklyn no Restaurante Meating, na Gávea

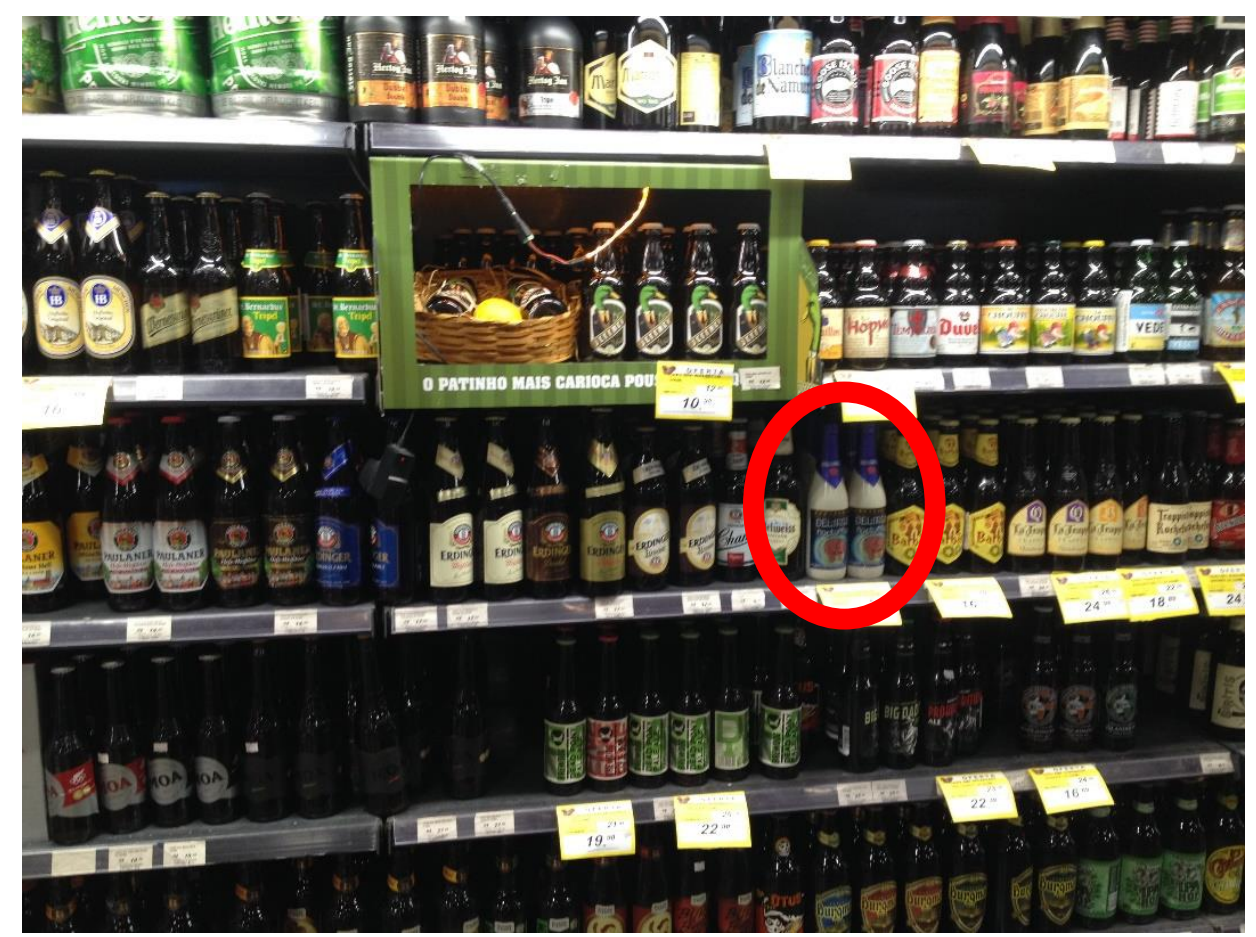

Figura 5: Ativação da Jeffrey (e presença discreta da Delirium) no mercado Zona Sul, no Leblon 


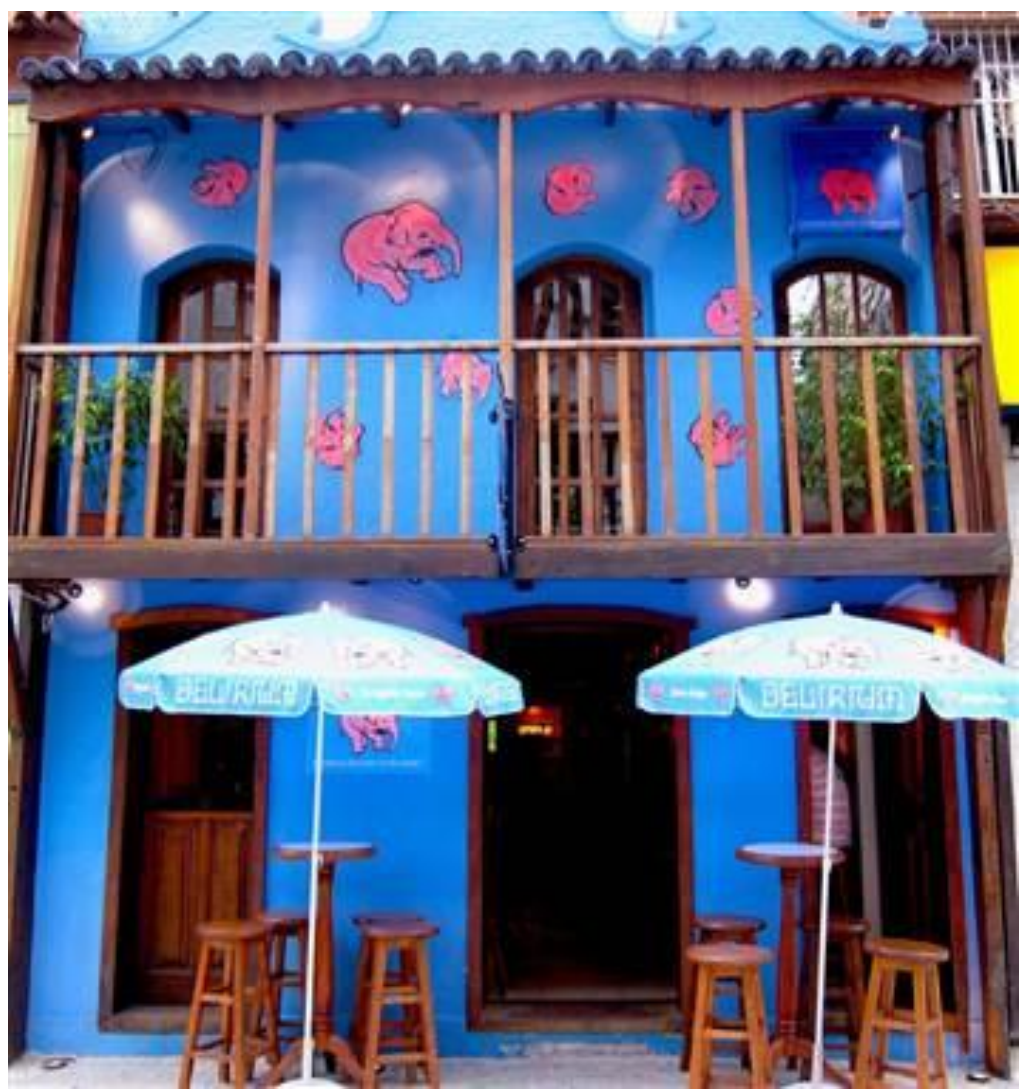

Figura 6: Delirium Café, em Ipanema

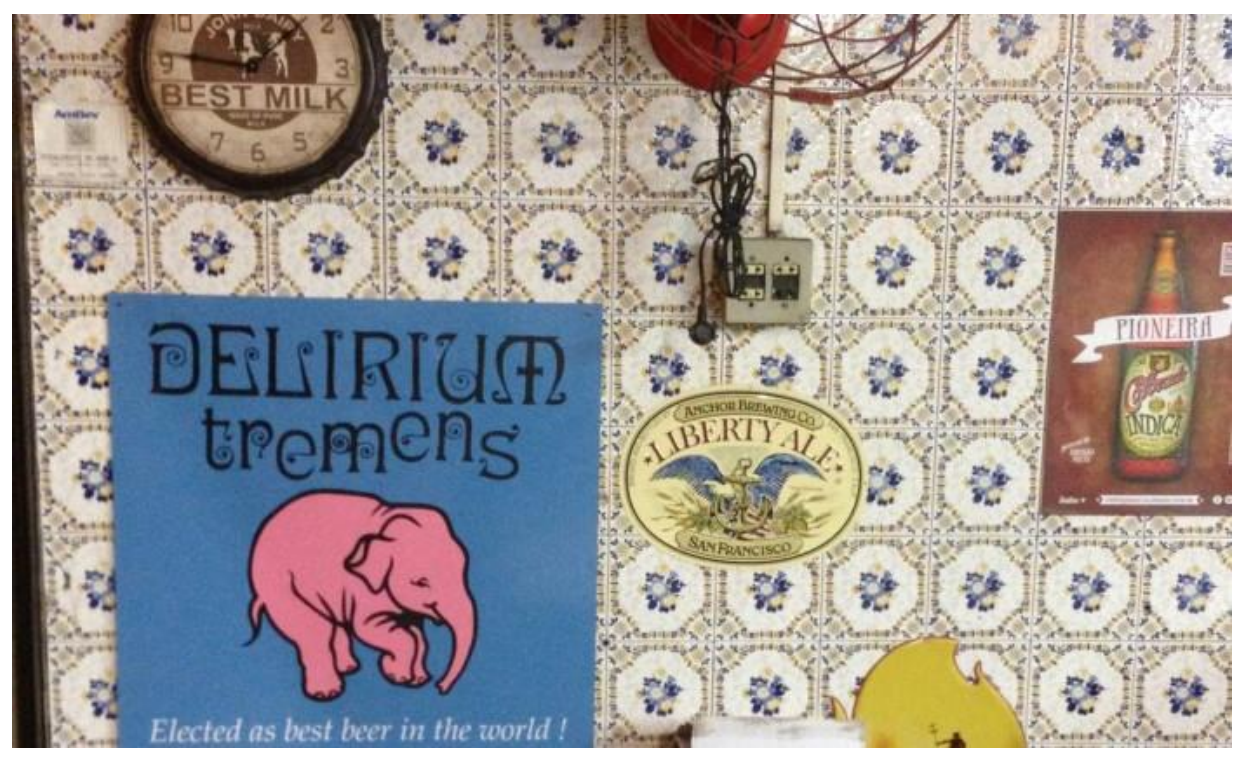

Figura 7: Exposição da Delirium no Bar Brewteco, no Leblon 


\subsection{A Experiência}

Inicialmente, foi pedido ao grupo que levantasse alguns critérios que influenciassem na escolha de uma cerveja artesanal. Posteriormente, ocorreu uma votação, na qual foram determinados os 4 critérios mais importantes dentro do grupo previamente levantado. $O$ conjunto inicial era composto por:

I. Tipo/Familia da Cerveja: Lager, Ale, Pilsen, Witbier, etc.;

II. Propaganda: Exposições da marca no ambiente de consumo, que pode variar de um letreiro a um descanso de copo com a logo da cerveja;

III. Embalagem: o estilo da embalagem, seu tamanho, formato e cor, além do rótulo e tampinha;

IV. Indicação: pessoas que te aconselham e persuadem a beber determinada marca;

V. Marca: a imagem que a marca tem no mercado

VI. Sabor: o gosto da cerveja em si;

VII. After Taste: o gosto que fica depois do gole;

VIII. Cor do Líquido: clara, escura, turva, avermelhada, etc.;

IX. Teor Alcoólico: porcentagem de álcool na cerveja.

Destes, o escolhido grupo de 4 critérios mais relevantes foi:

Propaganda

Embalagem

Indicação

Sabor

É importante salientar que o grupo foi orientado a não colocar na análise o quesito Preço, pois o MAH visa conduzir o processo decisório com fatores nãonuméricos, e utilizar o fator monetário apenas no final para realizar uma avaliação custo benefício baseada nos pesos adquiridos anteriormente.

Para dar seguimento ao experimento, o grupo de 10 pessoas foi apresentado às cervejas (lembrando que todos já tiveram contato com as três marcas antes na vida) e em seguida foi realizada a degustação da seguinte forma: cada pessoa recebeu 3 taças e experimentou uma de cada vez, iniciando com a Jeffrey, seguida da Delirium Tremens e por último a Brooklin.

Após finalizado o processo de degustação, o grupo recebeu uma folha explicando que eles deveriam preencher o $\mathrm{MAH}$, que é composto por matrizes, 
nas quais, como já foi dito, o participante compara os critérios entre si atribuindo pesos.

Todos preencheram as matrizes de critérios, e logo após, completaram as matrizes das 3 alternativas dentro de cada um dos 4 critérios. O processo todo levou cerca de 40 minutos para ser concluído.

A estrutura de hierarquias foi montada de acordo com o que foi escolhido pelo grupo de foco e ficou desta forma:

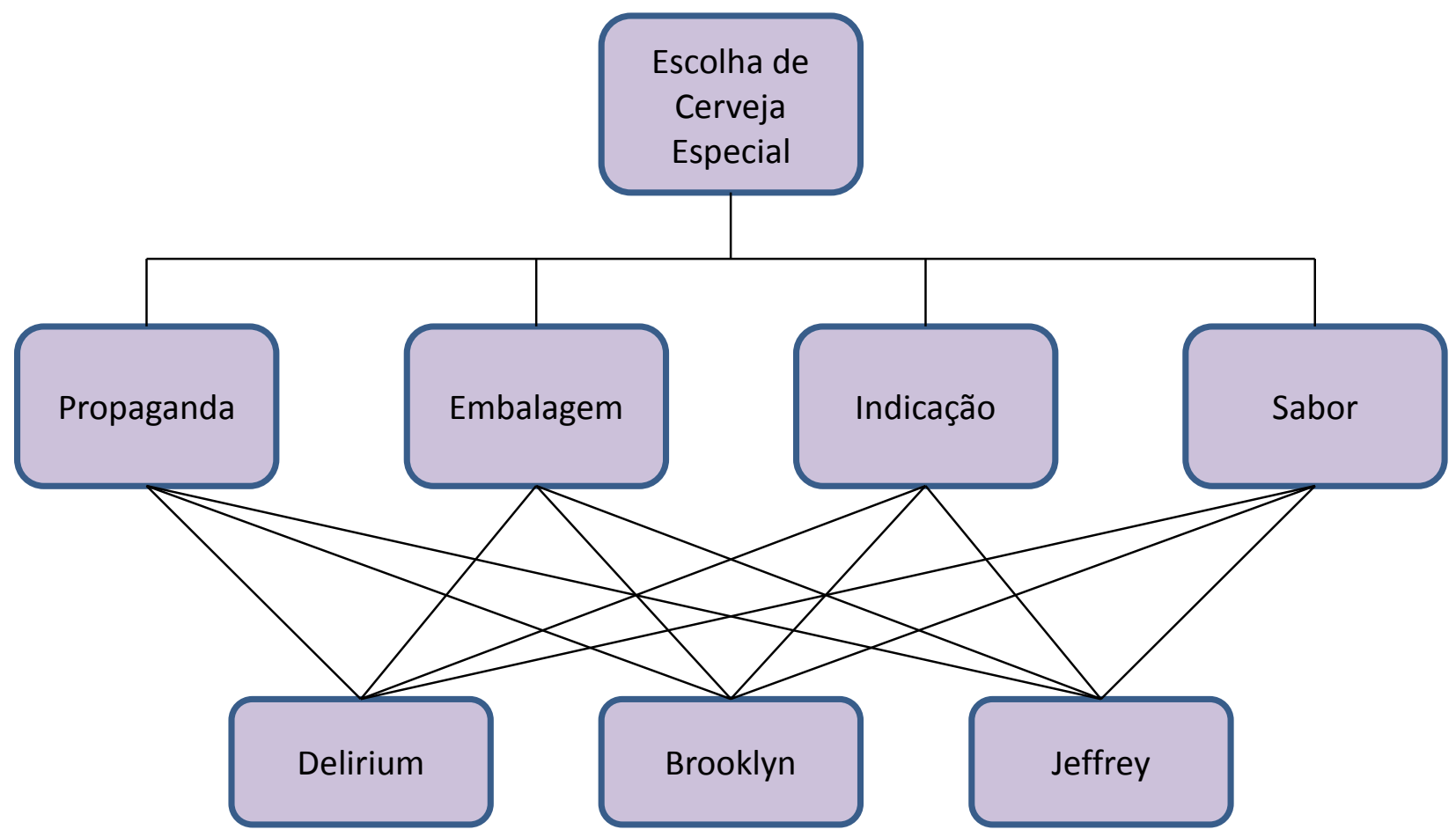

Figura 8: Hierarquia da Pesquisa

\subsubsection{Processo de Cálculo e Resultados}

As folhas preenchidas pelos participantes encontram-se no Anexo 1. Elas foram recolhidas e os dados computados em Microsoft Excel. As informações foram calculadas segundo o $\mathrm{MAH}$, que foi montado e automatizado no software. Os cálculos que serão mostrados a seguir apresentam a média dos valores respondidos pelos participantes. 
A primeira missão do grupo de foco era preencher a matriz de comparações, representadas abaixo:

\begin{tabular}{|c|c|c|c|c|}
\hline & Propaganda & Embalagem & Indicação & Sabor \\
\hline Propaganda & 1,0000 & 0,2000 & 0,2000 & 0,1429 \\
\hline Embalagem & 5,0000 & 1,0000 & 0,3333 & 0,2000 \\
\hline Indicação & 5,0000 & 3,0000 & 1,0000 & 0,2000 \\
\hline Sabor & 7,0000 & 5,0000 & 5,0000 & 1,0000 \\
\hline
\end{tabular}

Tabela 5: Matriz de Comparação de Critérios

Em relação a tabela acima, podemos aferir que o critério Propaganda é essencialmente menos importante em relação a Embalagem e da mesma forma para a Indicação. Além disso, os participantes avaliaram a Propaganda como muito menos importante que o Sabor.

Em relação ao critério Embalagem, os participantes disseram que este é moderadamente menos importante que Indicação e é essencialmente menos importante que o Sabor.

No critério Indicação, além das análises feitas acima, temos que este é essencialmente menos importante que o critério Sabor.

Seguindo adiante, o passo seguinte consiste em elevar a Matriz dos Critérios ao quadrado, obtendo-se a Matriz Quadrada 1. Em seguida, é feita a soma de cada linha, e os pesos são calculados ao se fazer a normalização dos valores. Os cálculos estão na tabela a seguir:

\begin{tabular}{|c|c|c|c|c|c|}
\hline \multicolumn{4}{|c|}{ Matriz Quadrada 1} & Soma das Linhas & \multirow{2}{*}{$\begin{array}{c}\text { Pesos } 1 \\
0,0413\end{array}$} \\
\hline 4,0000 & 1,7143 & 1,1809 & 0,3657 & 7,2609 & \\
\hline 13,0665 & 3,9999 & 2,6666 & 1,1809 & 20,9139 & 0,1190 \\
\hline 26,4000 & 8,0000 & 3,9999 & 1,7143 & 40,1142 & 0,2282 \\
\hline \multirow[t]{2}{*}{64,0000} & 26,4000 & 13,0665 & 4,0000 & 107,4665 & 0,6115 \\
\hline & & & & 175,7556 & 1,0000 \\
\hline
\end{tabular}

Tabela 6: Matriz Quadrada 1 Normalizada 
Depois deve-se elevar a matriz quadrada 1 novamente ao quadrado, para que sejam obtidos os autovetores desejados. O processo de dupla extração da raiz quadrada ocorre para diminuir diferenças de informação e chegar a forma mais próxima da realidade.

\begin{tabular}{|c|c|c|c|c|c|}
\hline & \multicolumn{3}{|c|}{ Matriz Quadrada 2} & Soma das Linhas & Pesos 2 \\
\hline 92,9824 & 32,8165 & 18,7974 & 6,9747 & 151,5710 & 0,0468 \\
\hline 250,5095 & 90,9087 & 52,1939 & 18,7974 & 412,4094 & 0,1273 \\
\hline 425,4436 & 154,5127 & 90,9087 & 32,8165 & 703,6815 & 0,2173 \\
\hline 1201,9112 & 425,4436 & 250,5095 & 92,9824 & 1970,8467 & 0,6086 \\
\hline
\end{tabular}

Tabela 7: Matriz Quadrada 2 Normalizada

O passo seguinte é a subtração entre as matrizes Pesos 1 e Pesos 2, com a intenção de validar os dados, que foi o fato ocorrido, pois as diferenças verificadas são pequenas.

$\left.\begin{array}{c|c}\multicolumn{1}{c}{\text { Pesos 2 }} \\ \text { Propaganda } \\ \text { Embalagem } & 0,0468 \\ 0,1273 \\ \text { Indicação } & 0,2173 \\ \text { Sabor } & 0,6086\end{array}\right] \square\left[\begin{array}{c}0,0413 \\ 0,1190 \\ 0,2282 \\ 0,6115\end{array}\right] \square$

Tabela 8: Vetor Prioridade

Pode-se aferir, a partir da tabela 8, a ordem de importância dos critérios para o grupo de foco, de acordo com os pesos da matriz Pesos 2. Portanto, temos em primeiro lugar o Sabor com 61,15\%, seguido por Indicação com 22,82\%, Embalagem com 11,90\% e, por último, a Propaganda com 4,13\%

A etapa seguinte é de comparação das marcas, que são as alternativas, dentro de cada critério, separadamente, para saber quais se destacam em relação às outras. 


\section{Propaganda}

Neste critério a Delirium foi considerada pelos participantes como essencialmente mais importante que a Brooklyn, mas moderadamente menos importante que a Jeffrey, que por sua vez, foi considerada essencialmente mais importante que a Brooklyn.

$\left.\begin{array}{c|ccc} & \multicolumn{3}{c}{\text { Propaganda }} \\ \text { Delirium } & \text { Delirium } & \text { Brooklyn } & \text { Jeffrey } \\ \text { Brooklyn } & 1,0000 & 5,0000 & 0,3333 \\ \text { Jeffrey } & 0,2000 & 1,0000 & 0,2000 \\ 3,0000 & 5,0000 & 1,0000\end{array}\right]$

Tabela 9: Matriz Propaganda

\section{Embalagem}

No critério Embalagem a Delirium foi dita como essencialmente mais importante que a Brooklyn e moderadamente mais importante que a Jeffrey. Para completar, a Jeffrey foi considerada moderadamente mais importante que a Brooklyn neste critério.

\begin{tabular}{|c|c|c|c|}
\hline & \multicolumn{3}{|c|}{ Embalagem } \\
\hline & Delirium & Brooklyn & Jeffrey \\
\hline Delirium & 1,0000 & 5,0000 & 3,0000 \\
\hline Brooklyn & 0,2000 & 1,0000 & 0,3333 \\
\hline Jeffrey & 0,3333 & 3,0000 & 1,0000 \\
\hline
\end{tabular}

Tabela 10: Matriz Embalagem 


\section{Indicação}

Quanto ao critério Indicação, os participantes disseram que a Delirium é essencialmente mais importante que a Brooklyn e moderadamente menos importante que a Jeffrey. A Jeffrey, por sua vez, foi considerada moderadamente mais importante que a Brooklyn em termos de indicação de terceiros.

$\left.\begin{array}{cccc} & \multicolumn{3}{c}{\text { Indicação }} \\ \text { Delirium } & \text { Delirium } & \text { Brooklyn } & \text { Jeffrey } \\ \text { Brooklyn } & 1,0000 & 5,0000 & 0,3333 \\ \text { Jeffrey } & 0,2000 & 1,0000 & 0,3333 \\ 3,0000 & 3,0000 & 1,0000\end{array}\right]$

Tabela 11: Matriz Indicação

\section{Sabor}

No critério Sabor, a Delirium foi dita pelos participantes como essencialmente superior que a Brooklyn e moderadamente inferior a Jeffrey. $O$ Sabor da Jeffrey foi considerado moderadamente superior a Brooklyn.

\begin{tabular}{|c|c|c|c|}
\hline & \multicolumn{3}{|c|}{ Sabor } \\
\hline & Delirium & Brooklyn & Jeffrey \\
\hline elirium & {$[1,0000$} & 5,0000 & 0,3333 \\
\hline Brooklyn & 0,2000 & 1,0000 & 0,3333 \\
\hline Jeffrey & 3,0000 & 3,0000 & 1,0000 \\
\hline
\end{tabular}

Tabela 12: Matriz Sabor

Os passos seguintes acontecem da mesma forma que ocorreu anteriormente para calcular os pesos dos critérios: as matrizes quadradas de cada alternativa são calculadas, em seguida, elevadas novamente ao quadrado, até que suas linhas são somadas, resultando na tabela da página 33 , com os pesos finais de cada alternativa dentro de cada critério. 


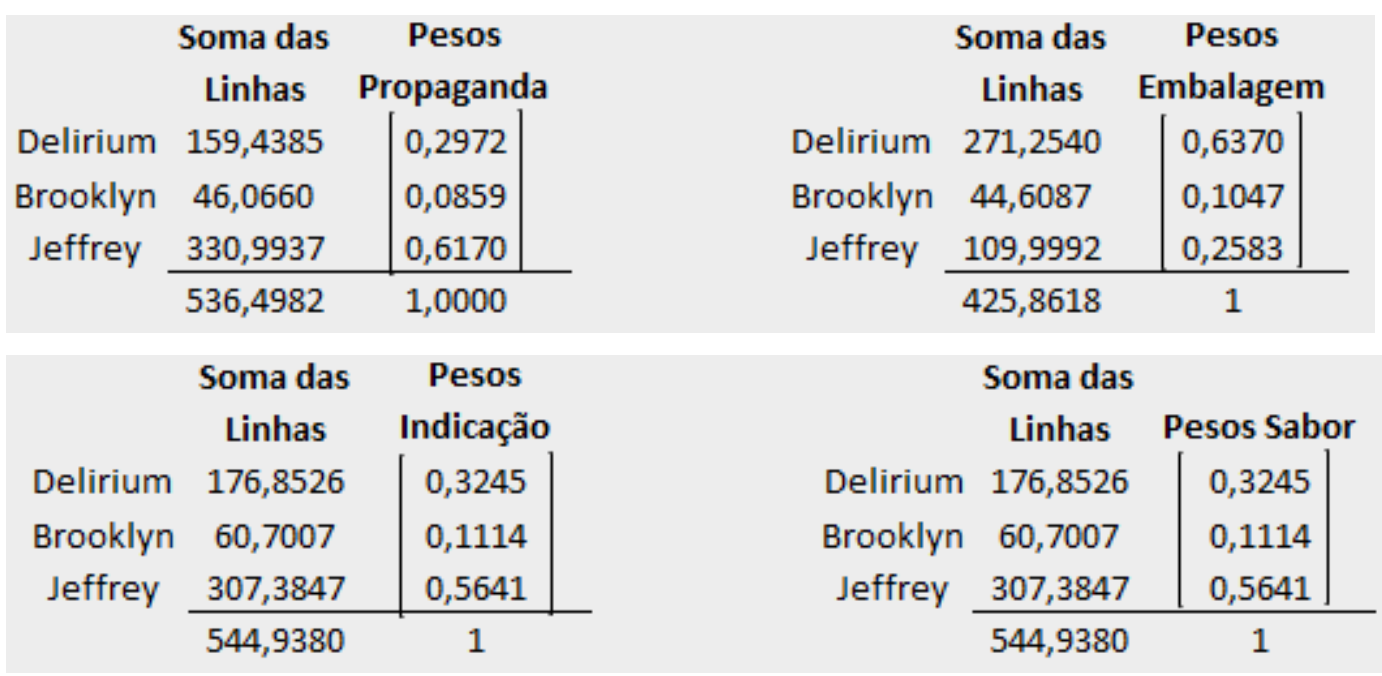

Tabela 14: Vetores Prioridade das Alternativas

Pode-se perceber que no critério propaganda a Jeffrey levou a melhor com $61,70 \%$, seguida da Delirium com $29,72 \%$ e por último a Brooklyn com $8,59 \%$.

No critério Embalagem a Delirium ficou em primeiro com $63,70 \%$, a Jeffrey em segundo com 25,83\% e a Brooklyn, em último com 10,47\%.

No critério Indicação, a Jeffrey ganhou com $56,41 \%$, seguida da Delirium com $32,45 \%$ e por último a Brooklyn com 11,14\%.

E por fim, no critério Sabor, a Jeffrey venceu com $56,41 \%$, com Delirium em segundo $32,45 \%$ e Brooklyn em terceiro com 11,14\%.

Nota-se que os valores de Indicação e Sabor foram idênticos e classificados na mesma ordem de marcas.

Para finalizar os cálculos, é montada a Matriz Decisiva (Tabela 14 abaixo), que é multiplicada pelos pesos de cada critério, que foram calculados previamente e, desta forma, chega-se à conclusão. 


\begin{tabular}{|c|c|c|c|c|c|c|c|c|}
\hline & Propaganda & Embalagem & Indicação & Sabor & Pesos 2 & & & \\
\hline Delirium & 0,2972 & 0,6370 & 0,3245 & 0,3245 & 0,0468 & & 0,3630 & Delirium Tremens \\
\hline Brooklyn & 0,0859 & 0,1047 & 0,1114 & 0,1114 & 0,1273 & 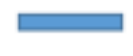 & 0,1093 & Brooklyn Lager \\
\hline Jeffrey & 0,6170 & 0,2583 & 0,5641 & 0,5641 & $\begin{array}{l}0,2173 \\
0,6086\end{array}$ & & 0,5276 & Jeffrey Niña \\
\hline
\end{tabular}

Tabela 15: Matriz Decisiva

Como resultado final do modelo, a escolhida foi a Jeffrey Niña, destacada acima na cor verde, com 52,76\% da preferência dos participantes, seguido pela Delirium Tremens com 36,30\%, e por último a Brooklyn Lager com apenas $10,93 \%$. 


\section{Conclusões e recomendações para novos estudos}

Este capítulo visa resumir e concluir tudo que foi apresentado e analisado anteriormente. O Estudo realizado se propôs a responder a seguinte questão: quais são os principais fatores que influenciam o comportamento do consumidor jovem de cervejas especiais na Zona Sul do Rio de Janeiro?

Foi feita uma pesquisa acerca dos diversos fatores que poderiam explicar as formas de consumo do público-alvo em questão, levando em consideração fatores internos e externos aos indivíduos, ou seja, tanto pensamentos e percepções próprias como, por exemplo, influências de outras pessoas sobre sua forma de consumir.

Para responder a todas as dúvidas apresentadas, foi utilizado o Método de Análises de Hierarquias de Thomas Saaty, que necessitou a colaboração de um grupo de foco composto por 10 pessoas, escolhido rigorosamente dentro dos padrões estabelecidos de idade entre 20 e 30 anos, pertencentes às classes A e $B$, moradores ou frequentadores da Zona Sul do Rio de Janeiro. Foi fornecido um formulário aos participantes, que o preencheram de acordo com suas preferências.

O resultado do modelo teve como vencedor a Jeffrey, que teve $52,76 \%$ da preferência, enquanto a Delirium Tremens teve 36,30\% e a Brooklyn Lager conquistou $10,93 \%$. Pode-se aferir que este resultado se deveu muito ao critério Sabor, que foi o mais valorizado, no qual a Jeffrey obteve supremacia. Além disso, a cerveja carioca levou a melhor nos critérios Indicação e Propaganda, sendo superada apenas no critério Embalagem pela Delirium Tremens.

Algumas conclusões interessantes puderam ser realizadas após a apuração dos resultados:

- A primeira conclusão deste trabalho é um estímulo aos indivíduos que desejam ser empreendedores e entrar no ramo cervejeiro. Isto porque a comparação das marcas que mais se destacaram no trabalho é semelhante a um duelo entre Davi e Golias. Ao compararse a Jeffrey, cerveja carioca com pouco mais de 1 ano de existência, com uma gigante do cenário cervejeiro mundial, a tradicional 
Delirium Tremens, o que se percebeu foi que é possível competir com concorrentes grandes. Portanto, o crescimento exponencial do mercado nacional e o surgimento de milhares de cervejarias, tem uma razão de ser. Os grandes players sempre terão escala de vendas muito maior, mas é possível criar uma marca forte começando pequeno. Até porque, com a alta do dólar, a capacidade de penetração de produtos importados é reduzida, logo a competição estrangeira diminui.

- A propaganda, obviamente, tem grande valor no que se diz respeito à criação de brand awareness, comunicar os atributos do produto, cativar o público-alvo, entre outros fatores. Inclusive, este fator foi comprovado com a vitória da Jeffrey, que realiza mais ativações de marca que as concorrentes. Contudo, descobriu-se que a propaganda que mais tem valor não é a paga, e sim a gratuita, o famoso marketing boca-a-boca, que demonstrou muita importância na pesquisa, pois o critério Indicação - que abrange as situações em que outras pessoas indicam uma cerveja ao consumidor - foi o segundo colocado na pesquisa, perdendo apenas para o critério Sabor.

- Por falar em Sabor, descobriu-se que este é o mais importante dentre todos os outros critérios. Isto leva a uma conclusão que diz respeito também ao item anterior, a indicação. Pode-se concluir que as empresas do ramo de cerveja devem buscar e investir incessantemente em um sabor marcante. Obviamente, de acordo com o gênero ou idade, as preferências quanto ao paladar podem ser diversas, mas entre todas elas há um consenso: sabor importa, e muito. A relação com a indicação é simples, se o sabor de uma cerveja é tão bom que faz uma pessoa pedir sempre, ela certamente irá indicar a todos os seus grupos de referência que experimente. Este foi percebido, após análise do estudo, como o maior poder de atração para o consumo. A dupla Sabor e Indicação, juntas, podem ser consideradas responsáveis por grande parte do consumo de cervejas especiais na Zona Sul do Rio de Janeiro, para pessoas de 20 a 25 anos de idade, segundo os entrevistados. 
- Outras considerações sobre o Sabor: as mulheres tendem a preferir cervejas com o paladar mais leve e toques frutados, isto porque as 3 mulheres do experimento preferiram a Jeffrey, que possui limão siciliano e coentro em sua receita. Em contrapartida, cervejas encorpadas com sabor acentuado tendem a afugentar o público feminino, que não teve bons julgamentos em relação à Brooklyn.

\subsection{Sugestões e recomendações para novos estudos}

Seria interessante que mais estudos e artigos sobre o mercado de cervejas artesanais fossem feitos e publicados. Houve dificuldade em encontrar trabalhos acadêmicos sobre o tema e foi preciso utilizar bibliografia mais focada em reportagens.

Além disso, como o Brasil é um país extremamente diversificado, seguramente o comportamento do consumidor da Zona Sul do Rio de Janeiro não é igual ao de Porto Alegre, ou o de Minas Gerais. Por isso, seriam importantes estudos similares em outras regiões do país. 


\section{Referências Bibliográficas}

SCHOEMAKER, Paul JH; WAID, C. Carter. An experimental comparison of different approaches to determining weights in additive utility models.Management science, v. 28, n. 2, p. 182-196, 1982.

SCHIFFMAN, Leon G.; KANUK, Leslie Lazar. Comportamiento del consumidor. Pearson Educación, 2005.

SOUZA, A. R. C.; FARIAS, J. M. P.; NICOLUCI, T. C. Principais fatores que influenciam os consumidores universitários a frequentarem bares noturnos na cidade de Presidente Prudente. São Paulo. Monografia (Grau de Bacharel em Administração). Faculdade de Ciências Econômicas e Administrativas de Presidente Prudente. Faculdades Integradas "Antônio Eufrásio de Toledo". Presidente Prudente, 2005.

RENNÓ, Flávia SA. Os fatores socioculturais e situacionais e seu impacto no comportamento do consumidor jovem em relação ao vestuário. 2009. Tese de Doutorado. Dissertação (Mestrado profissional em Administração). Faculdades Integradas de Pedro Leopoldo. Pedro Leopoldo.

KOTLER, Philip; ARMSTRONG, Gary. Marketing Estratégico. Parte II, 2008.

CHAUVEL, Marie Agnes; MATTOS, M. P. A. Z. Consumidores de baixa renda: uma revisão dos achados de estudos feitos no Brasil. Cadernos Ebape, v. 6, n. 2, p. 1-16, 2008.

FRANCISCHELLI, P. A importância da marca no processo de decisão de compra de calçados esportivos para a população de baixa renda. 2009. $120 \mathrm{f}$. 2009. Tese de Doutorado. Dissertação (Mestrado em Administração)-Programa de Mestrado Executivo em Gestão Empresarial da Fundação Getulio Vargas, Rio de Janeiro. 
BARROS, Carla Fernanda. Classificação de restaurantes a partir da visão do consumidor: um estudo etnográfico. ENCONTRO NACIONAL DE PROGRAMAS DE PÓS-GRADUAÇÃO E PESQUISA EM ADMINISTRAÇÃO, v. 28, 2004.

SOLOMON, Michael R. Consumer Behavior International Edition. Prentice Hall, New Jersey, Chapters 7 \&, v. 9, 2002.

KOTLER, Philip; KELLER, Kevin Lane. Administração de marketing. 2006.

SAMARA, Beatriz Santos; MORSCH, Marco Aurélio. Comportamento do consumidor: conceitos e casos. São Paulo: Pretince Hall, 2005.

LIMEIRA, T. M. V. . Comportamento do Consumidor Brasileiro. 1. ed. São Paulo: Saraiva S/A Livreiros e Editores, 2007. v. 1. 380p .

DE OLIVEIRA LOPES, Kenya Gomes; COELHO, Márcia Maria Lara Pinto; LIBÂNIO, Marcelo. Aplicação do Método da Análise Hierárquica na Priorização da Reabilitação de Redes de Distribuição de Água.

http://www.infobeer.net/\#!ales-e-lagers/c1xok

http://www.gelchopp.com.br/curiosidade/alta-e-baixa-fermentacao/

http://www.maxwell.vrac.puc-rio.br/17608/17608_5.PDF

http://www.brejas.com.br/cerveja/belgica/delirium-tremens

http://repositorio.ipv.pt/bitstream/10400.19/1815/1/Tese_Miguel_MKT_Vinh o_Final_dp_defesa.pdf

http://pme.estadao.com.br/noticias/noticias, promissor-mercado-dascervejas-artesanais-atrai-cada-vez-mais-empreendedores,3463,0.htm

http://exame.abril.com.br/pme/noticias/em-busca-de-1001-cervejasamigos-criam-negocio-de-r-3-mi/ 
http://exame.abril.com.br/revista-exame-pme/edicoes/76/noticias/com-ocopo-cheio

http://g1.globo.com/rj/regiao-serrana/noticia/2014/04/mercado-de-cervejaspremium-no-brasil-esta-em-franca-fermentacao.html

Be-a-bá da cerveja: conheça os tipos e variedades: https://www.youtube.com/watch?v=QOAQapfAb_w

http://www.lume.ufrgs.br/bitstream/handle/10183/117297/000966638.pdf?s equence $=1$ 


\section{Anexo 1 - Folha Entregue aos Participantes (3 páginas)}

Pesquisa de Comportamento do Consumidor

Nome:

Idade:

Marcas Utilizadas

Delirium Tremens

Brooklyn Lager

Jeffrey Niña

\section{Critérios de Comparação:}

a) Tipo/Família da Cerveja: Ale, Lager, Wit Bier, IPA, etc...

b) Propaganda: Presença da logomarca no ponto de venda.

c) Embalagem: Tamanho, estilo, rótulo

d) Indicação: Amigos, familiares, garçon, etc...

e) Marca

f) Sabor

g) After Taste: $\mathrm{O}$ gosto que fica depois do gole.

h) Cor do Líquido

i) Sugestão (?):

1) Comparando em pares na matriz abaixo, faça uma análise de importância de um critério em relação ao outro, sendo:

1 - Igual 3 -Moderado 5 -Forte 7 - Muito Forte 9 - Extremo

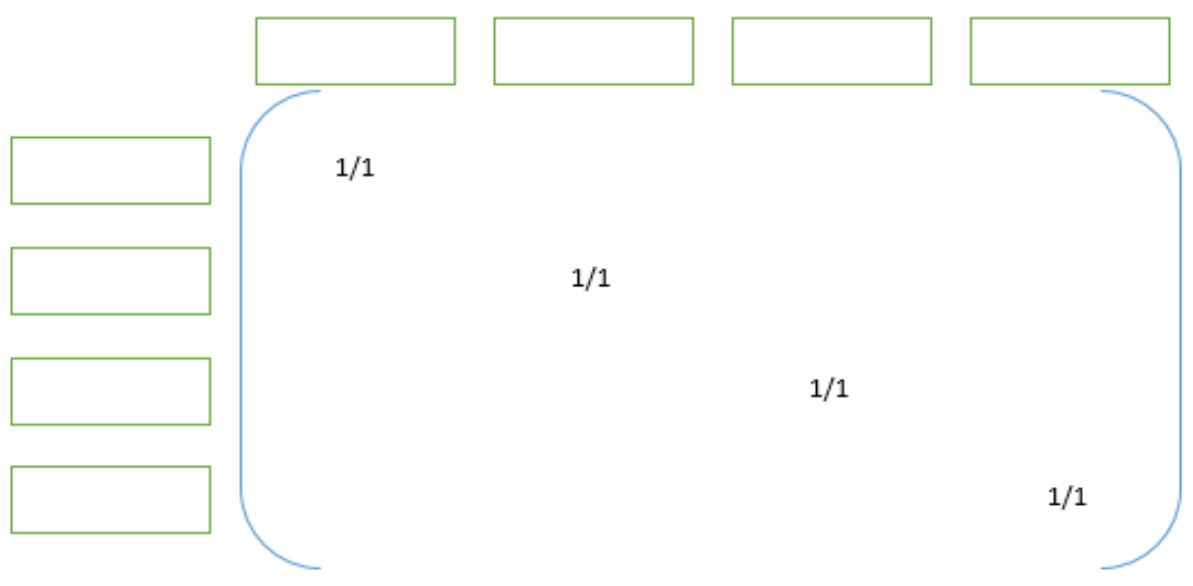


2) Repita o mesmo processo, agora comparando as marcas dentro de cada critério

Critério:

\begin{tabular}{|c|c|c|c|}
\hline & $\begin{array}{l}\text { Delirium } \\
\text { Tremens }\end{array}$ & $\begin{array}{c}\text { Brooklyn } \\
\text { Lager }\end{array}$ & Jeffrey \\
\hline $\begin{array}{l}\text { Delirium } \\
\text { Tremens }\end{array}$ & $1 / 1$ & & \\
\hline $\begin{array}{c}\text { Brooklyn } \\
\text { Lager }\end{array}$ & & $1 / 1$ & \\
\hline Jeffrey & & & $1 / 1$ \\
\hline
\end{tabular}

Critério:

$\begin{array}{lcc}\begin{array}{c}\text { Delirium } \\ \text { Tremens }\end{array} & \begin{array}{c}\text { Brooklyn } \\ \text { Lager }\end{array} & \text { Jeffrey } \\ \text { Delirium } \\ \text { Tremens } \\ \text { Brooklyn } \\ \text { Lager } \\ \text { Jeffrey }\end{array}$




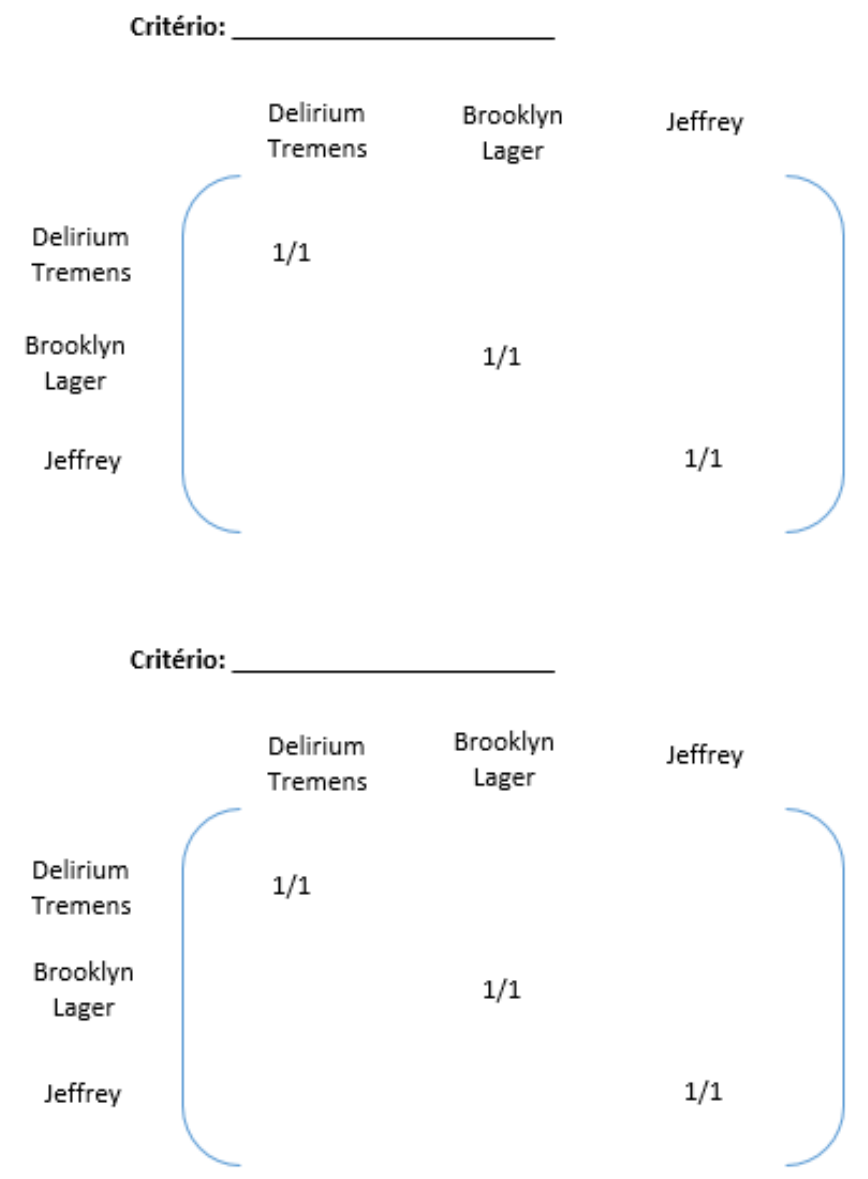

OBRIGADO! 